\title{
Evolutionary Dynamics of Interfirm Cooperative System for Radical Innovation from Knowledge Collaboration Perspective
}

\author{
Jinsheng Li, ${ }^{1}$ Yi Shi, ${ }^{1}$ and $\mathrm{Lu} \mathrm{Xu} \mathbb{1 i}^{2}$ \\ ${ }^{1}$ Business School, Nanjing Normal University, Nanjing, China \\ ${ }^{2}$ Office of Academic Affairs, Nanjing Institute of Railway Technology, Nanjing, China \\ Correspondence should be addressed to Lu Xu; nj_xulu@163.com
}

Received 14 May 2020; Accepted 1 July 2020; Published 13 August 2020

Guest Editor: Shouwei Li

Copyright (c) 2020 Jinsheng Li et al. This is an open access article distributed under the Creative Commons Attribution License, which permits unrestricted use, distribution, and reproduction in any medium, provided the original work is properly cited.

Interfirm cooperation can be seen as a significant and effective way for exploring radical innovation. In this article, a framework of interfirm cooperation, with a core manufacture and upstream counterparties in industry, and its evolving mechanism in the reverse-chain radical innovation are established from the perspective of the fundamental role played by knowledge collaboration. Then, an evolution model of interfirm cooperation is constructed on the theory of vibration mechanics, and its evolutionary dynamics is explored through numerical and simulation analysis mainly on the key factors of knowledge potential difference and knowledge rent-seeking behaviour within the firms. The findings show that, if there is no knowledge-based rent-seeking behaviour from the upstream firms, the probable innovative performance from the interfirm cooperation should vary for the knowledge potential difference between the cooperative firms, but can come to a certain equilibrium state. Meanwhile, if the knowledge rentseeking behaviour does exist, knowledge potential difference would lead the innovative performance evolving ultimately in divergence. What's more, the negative effect caused by the rent-seeking behaviour could be alleviated or weakened to some extent by the excitation mechanisms presented by the core firms in the cooperation system. Therefore, the drawn conclusions should be useful for the core manufactures' implementing various strategies to maintain or enhance the cooperation for radical innovation in industry.

\section{Introduction}

Radical innovation has been conceptualized as substantive changes in technology that advance frontiers by much more than the existing rate of progress $[1,2]$. It also has been characterized by a market perspective, which emphasizes a new innovative system, strategy, and market positioning in the nonmainstream market and damages the competitiveness in the existing market [3]. With the widespread application of a new generation of technologies in society and economy, the original source of radical innovation can be achieved efficiently and intensely through various kinds of cooperation between the firms $[4,5]$ for there being extremely difficult for single organization's innovation in isolation [6-10]. Interfirm cooperation can be achieved by breaking down the barriers of traditional organizational patterns in enterprises at different scales $[11,12]$, requiring relatively lower transaction costs than in pure market-based transactions $[13,14]$, especially for the emerging markets, who have almost definitely comparative advantages in some high-tech industries [15]. In the information age with knowledge-based economy, firms assimilate knowledge in the form of innovations much faster than in the past. The firms from high-technological industries, with higher levels of absorptive capacity and of innovation investment, place greater value on cooperation partners in the innovation process [16]. Meanwhile, it has already been acknowledged that innovation should be a highly uncertain and complex process which involves knowledge recombination significantly [17] and other series of synthetic activities, through which the cooperators could potentially learn from each other $[18,19]$ and boost focal firms' innovation performance $[20,21]$. Therefore, radical innovation raises high standard level for effective cooperation over each firm and should 
benefit all of the partners through it, including accessing complementary resources and risk sharing, thereby improving the probability of success in the innovation projects, and even unintended surprise $[22,23]$. Due to peripheral and small firms' lack of resources or long-term motivation and their insufficient size to develop and introduce radical innovations, cooperation with other counterparties and larger companies is a basic strategy for developing capabilities in alliance portfolio management [24], especially for the firms in the whole knowledge-intensive industry chain. Thus, a special cooperative pattern with one core manufacture (seldom) and amount of periphery firms (upstream or downstream firms) in the industry chain has already been established or incubated in various markets for innovation. Scholars such as Bouncken et al. [25] have shown that "coopetition" improves innovation performance in knowledge-intensive firms or industries, especially those that operate in clusters.

Concerning the knowledge-intensive radical innovation, firms have to engage with different types of partners to acquire resources [26] whoever they are and whomever they are belonging to, especially for the increasing complexity of knowledge and technology nowadays $[27,28]$. Through the cooperation, all firms can share their own acquired knowledge and then incorporate the knowledge from outside their boundaries so as to promote the innovation performance [29, 30]. Accordingly, it is crucial for firms' capacity to transform amount of possible useful information into valuable knowledge, which could also be a significant determinant of firms' decisions for cooperation. Until now, lots of literatures have been focused on the determinants of cooperation or even "coopetition" and emphasized the relationships between knowledge and innovation $[16,25,31-35]$. Basically, almost all these related researches have paid more attention on the characteristics of the classified knowledge, the pathway of this knowledge being originated or absorbed, and the role of kinds of knowledge on firms' strategies in sort of cooperation patterns [26, 36, 37].

Knowledge-related researches have already provided a theoretical basis for understanding how knowledge necessitates interfirm collaboration [38-40]. Particularly, in knowledge-intensive technological industrial fields, it is plausible to assume that the underlying knowledge affects the collaboration and cooperation propensity, as well as the innovation [41]. Normally, a firm's stock of knowledge influences its decision to cooperate and its choice of partners, which means a technologically fitted partner should directly influence a firm whether to stop searching for partners or not. Besides, a firm's knowledge base determines its suitability to be a potential partner in cooperation, that is to say the firms' internal knowledge deficiencies and externally available complementarities play a significant role in the emergence of cooperation and innovation. Therefore, it is crucial to preserve the quantity and diversity of knowledge for innovation system, and the cooperation formation is driven by its probability to succeed in terms of knowledge generation and innovation, as well as the proximity of the potential partner $[42,43]$. On this basis, no matter how the knowledge being presented, the effectiveness of the cooperation should be influenced by the subjective factors of each firm absolutely, especially on the cognitive distance, investment allocation of dealing with the knowledge, and the motivation or willingness to participate in that [44], which results in the firms selecting partners on sort of balanced principle of neither too close in the knowledge space (to facilitate novelty) nor too far away (to foster understanding ability). What's more, firms' knowledge bases show similar features as they cooperate more frequently [44-46], and the knowledge overlap may be greater than its initial cooperative level because of the mutual knowledge exchange and share over time. Therefore, cooperating firms may become so close that the knowledge potential of their partnership becomes too low to permit recombinant novelty [47].

In all, mainstream literatures have provided us with crucial insight into the nature and importance of knowledge [48] and reasons of cooperation for innovation from transaction cost perspectives [49], comprising the relationship within knowledge generation, cooperation formation, partners' selection, and how these factors influence the cooperation, no matter the exogenous effect or endogenous effect $[50,51]$. Actually, the complex phenomenon of cooperation comes to a widespread reality in today's business world, and understanding the cooperation on knowledge requires a more firm-focused and systemic perspective. For now, only a few literatures have paid attention to dynamics of the interfirm cooperation on knowledge from the complex science perspectives so as to analyse the essential way for innovation [35, 51-55], which should also be interesting or helpful for exploring the intrinsic mechanism of cooperation. From systemic perspective, combined with the classical knowledge-based viewpoint, it has been acknowledged that the dynamics of cooperation networks system as well as the dynamics on the system should be taken into account $[56,57]$, and the individual collaboration processes of firms at the microlevel depend on the structure of knowledge allowed for considering the cooperation system [41].

Since the increasingly competitive, complex, and uncertain business environment makes collaboration between firms an attractive strategy for the firms, industries, and markets to give proper response to the crises and seize the opportunities [24, 58-60], the application of an evolutionary economic and complex nonlinear scientific perspective provides additional and complementary insights into knowledge discovery and innovation process for industries. Thus, the proposed question in this article we want to examine is straightforward: how these factors in knowledge creating process interact and influence the innovation performance of the cooperation system? How the evolutionary dynamics of the cooperation system comes out by the activities of the firms on the knowledge collaboration? In this article, from the theory of complex science and vibration mechanics in physics, the mechanism of knowledge collaboration and the pattern of the interfirm cooperation in reverse-chain radical innovation are established, comprising core high-tech manufacturers and the upstream suppliers. Based on that constructed interfirm cooperation model from knowledge collaboration, numerical and simulation analyses 
are conducted, so as to explore the evolutionary dynamics of the interfirm cooperative system for innovation. Although there are indeed some literatures focused on the complex characteristics of this subject, the theory and methods adopted in this paper are different from those studies, which are though mostly on the theory of multiagent, complex network, and nonlinear equation with different presumptions, and the conclusions also show significant differences from various indexes, which are used to depict the evolution of the interfirm cooperation system.

The rest of the paper is organized as follows: in Section 2, the mechanism of interfirm cooperation for innovation in knowledge collaboration is analysed. Section 3 constructs a dynamic model of interfirm cooperation on the theory of vibration mechanics. In Section 4, simulation on evolutionary dynamics of the interfirm cooperative system is conducted. The conclusions are drawn in Section 5.

\section{Mechanism of Interfirm Cooperative System on Knowledge Collaboration}

2.1. Framework of Interfirm Cooperation for Radical Innovation. On the existing analysis of the knowledge collaboration and the radical innovation, more deep exploration over their evolving mechanism that what the specific influential factors could be considered and how these possible factors intertwined within the system should be necessarily implemented. Concerning the high-tech interfirm cooperation system on knowledge collaboration, innovations probably emerge across this complex and systemic evolvement, including several stages for different functions and purposes [61, 62]. Therefore, knowledge collaboration could be seen as a systemic process that all the involved and necessary elements objective and subjective are combined in the organic way, which is crucial to the origin of the innovation and places different effects on the cooperation between the firms. Accordingly, from the theoretical analysis on the process of how the recognized knowledge emerges from various plain information [60, 63, 64], the knowledge collaboration process can be subtly divided into three interrelated and consecutive layers by the essential steps for its origin, including knowledge creation layer, knowledge integration layer, and knowledge interaction layer.

Knowledge creation layer is the first stage of the process, which is focused on the emerging of the knowledge from large amount of plain information. In this layer, the knowledge potential between each firm is initially developed mainly through knowledge acquisition, absorption, and conversion, implying a firm's capability of participating in interfirm cooperation. In this layer, each firm in the cooperation system participates in the cooperation activities, striving for the ongoing of knowledge creation in certain $\mathrm{R} \& \mathrm{D}$ fields. Following the first stage, the second stage of the knowledge collaboration process can be defined as the knowledge integration layer. In this layer, the motivation or willingness of the cooperators' participation in cooperation is driven by the knowledge potential, in which limited-rationality suppliers make the decision on different degrees of rent-seeking behaviour by different economic and social purposes. In the third and last stage of the knowledge collaboration process, knowledge interaction layer, the comprehensive ability for knowledge collaboration should influence the mutual coordination activities of the entire innovation system within the framework of interfirm cooperation. In general, each layer of knowledge collaboration will be conducted by all the participants in the cooperation system that can be realized in certain collaborative platform. Meanwhile, attribute to the participants' limited rationality, especially for the suppliers in high-tech industry, the capability, willingness, ability, and other features of the cooperators should lead to knowledge potential and knowledge-based rent-seeking behaviour in the cooperation. Thus, all the above analysis and the discussed aspects would contribute to the dynamic cooperation effect between interfirms in radical innovation through knowledge collaboration, and the framework and the mechanism can be shown in Figure 1 and the following sectors.

From the above analysis and the description of the knowledge collaboration system in interfirm cooperation, the framework and the mechanism of interfirm cooperation based on knowledge collaboration in the radical innovation system can be established and explored in Figure 1. From Figure 1, we can see that the bottom part represents the interfirm cooperation system, in which there are two types of firms, core manufacturers and their suppliers, in upstream and downstream industrial chain. For R\&D purpose, economic purpose, social purpose, and any other ones, they are committed (short-term or long-term) to cooperate with each other in some content to make breaking through innovation together, especially in high technology. Meanwhile, the knowledge collaboration system plays an extremely important role in interfirm cooperation for radical innovation, which has the essential characteristics of originality, progressiveness, exclusivity, and so on. Therefore, top part of Figure 1 demonstrates the simple structure of the knowledge collaboration system, whose progress comprises three steps or layers that are knowledge creation layer, knowledge integration layer, and knowledge interaction layer. However, the collaboration progress is directly affected by the cooperators' attribute, whose knowledge-based capability, collaborative willingness, collaborative ability, and other features are divergent objectively and subjectively. Thus, it leads to the possible influential factors to the cooperation that are knowledge potential difference, knowledge-based rent-seeking behaviour, and others, which could result in the complex dynamic effect of interfirm cooperation in the radical innovation system.

\subsection{Knowledge Collaboration Process in Interfirm} Cooperation. On the above framework about the interfirm cooperation on knowledge collaboration, a discussion will be presented over the knowledge collaboration process in this section, which is simply divided as the following three stages: knowledge creation stage, knowledge integration stage, and knowledge interaction stage by the sequence and the extent of the firms' cooperation on the knowledge for innovation. 


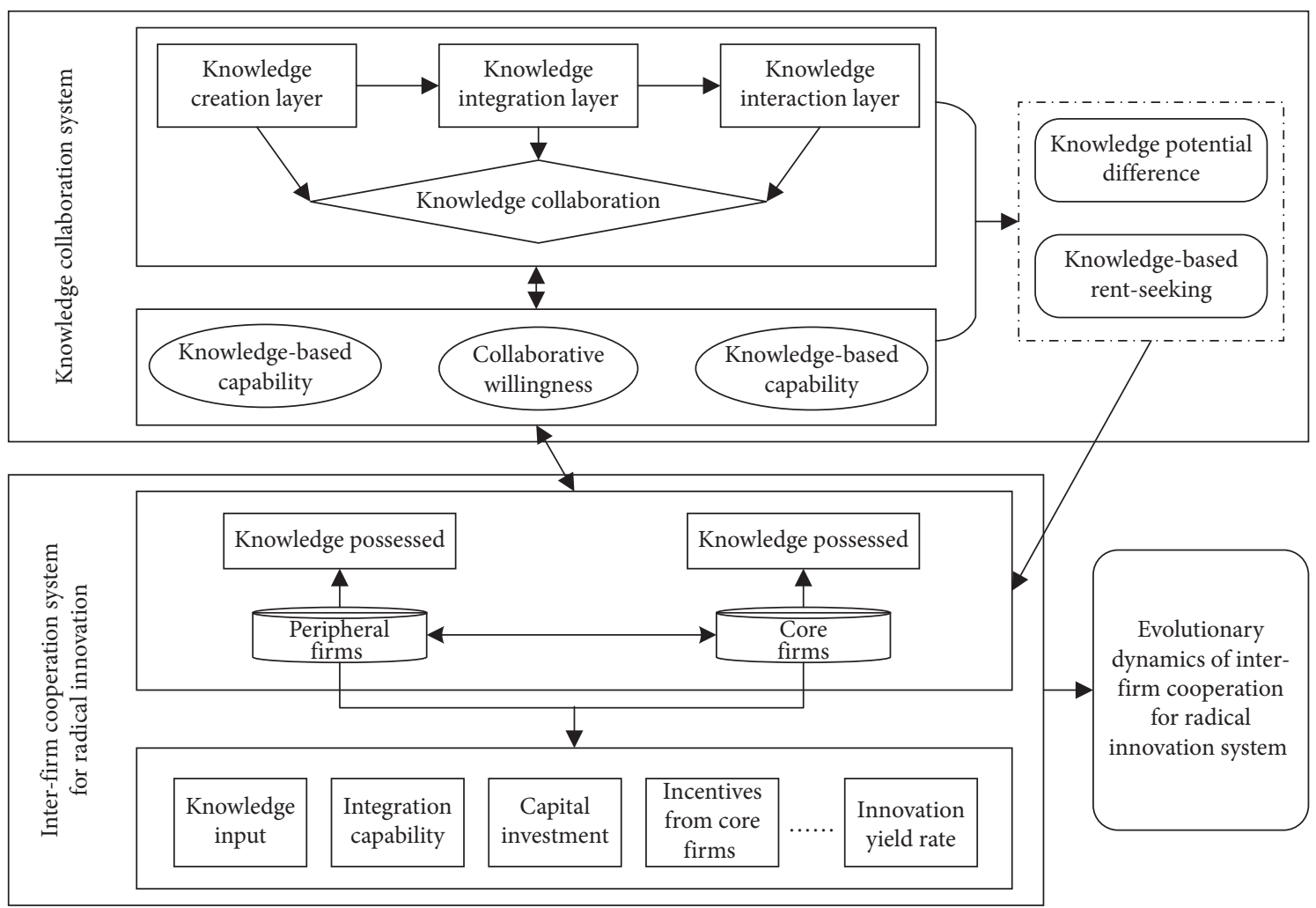

Figure 1: Framework of interfirm cooperation on knowledge collaboration for radical innovation.

Concerning each stage in the process of knowledge collaboration, it can also be seen as a special kind of $\mathrm{R} \& \mathrm{D}$ investment; therefore, the outcome of each stage should be recognized as a kind of agency for innovation performance.

\subsubsection{Knowledge Creation Stage in Interfirm Cooperation.} Knowledge creation stage is an early part in knowledge collaboration process, which is mainly focused on individual firms' investment to capture the knowledge creation on their own for some original innovation that can be seen as the R\&D activities by themselves. Therefore, endogenous growth model [65] is applied and updated that the factor of existed knowledge by the firms being taken into account to describe the knowledge creation stage in the cooperation:

$$
Y=D C^{\gamma} K^{\alpha} L^{\beta} e^{\lambda t+\mu}
$$

where let $Y$ be the level of knowledge creation; $C, K$, and $L$ be the input of $\mathrm{R} \& \mathrm{D}$ capital cost, existed knowledge, and human resources respectively; and $\gamma, \alpha$, and $\beta$ be the output elasticity coefficient with each variable. What's more, let $t, e$, and $D$ be the evolving time, natural logarithm, and constant variable, respectively. Thus, the knowledge creation for the core manufacturers $Y_{M}$ and the periphery suppliers $Y_{S}$ can be designed as follows:

$$
\begin{aligned}
Y_{M} & =D C_{M}^{\gamma} K_{M}^{\alpha} L_{M}^{\beta} e^{\lambda t+\mu}, \quad M \in(1,2, \ldots, k), \\
Y_{S} & =D C_{S}^{\gamma} K_{S}^{\alpha} L_{S}^{\beta} e^{\lambda t+\mu}, \quad S \in(1,2, \ldots, l) .
\end{aligned}
$$

However, it is presumed that there should be one core manufacturer and $n$ periphery suppliers in the cooperation system for simplicity. Meanwhile, according to the procedure of the knowledge creation, this stage can be separated into two parts that are the part of knowledge absorption and the part of knowledge conversion. Therefore, based on the above basic model about the knowledge creation, the detailed analysis on the interfirm cooperation about that can be conducted in the following sectors.

(1) Knowledge absorption:

As is known to all that the already obtained knowledge by each firm should be different, each agent in the cooperation system has to absorb the new knowledge from the partners or the outside and cope that with the peer partners so as to generate the new ideas or expected things. However, whether it can go through successfully or not, it depends on the firms' ability to handle this in the process of cooperation. Therefore, let $K_{M}$ and $K_{S}$ be the obtained knowledge what the core firm and periphery firms have, respectively; $L_{\mathrm{in}, M}$ and $L_{\mathrm{ex}, M}$ be the ability of the core firm's integrating internal knowledge and external knowledge, respectively; and $L_{\text {in, } S}$ and $L_{\text {ex }, S}$ be the ability of the periphery firms' integrating internal knowledge and external knowledge, respectively. Generally speaking, in the process of interfirm collaboration, each firm could absorb or obtain the external knowledge with the collaborate firms on their own ability; therefore, the close proportion of 
the knowledge owned by every two interacted firms, which is extremely important for the collaboration, can be defined as follows, respectively:

$$
\begin{aligned}
& \text { Couple }_{M}=\frac{\delta K_{S}}{K_{M}}, \\
& \text { Couple }_{S}=\frac{\delta K_{M}}{K_{S}},
\end{aligned}
$$

where $\delta K_{M}$ and $\delta K_{S}$ represent the scale of the needed knowledge from the coupling counterparty for periphery suppliers and core manufactures, respectively. Thus, for each periphery supplier, the knowledge absorption function can be expressed as

$$
K_{\text {Couple }}(s)=K_{M}^{\alpha^{\prime}} \operatorname{Couple}_{M}^{\alpha-\alpha} L_{\mathrm{in}, S}^{\beta^{\prime}} L_{\mathrm{ex}, S}^{\beta-\beta^{\prime}} C_{S}^{\gamma} e^{h(t)}
$$

Submitting equation (3) into equation (4), we can obtain the updated knowledge absorption function of the periphery supplier:

$$
K_{\text {Couple }}(S)=K_{M}^{2 \alpha^{\prime}-\alpha} \delta K_{S}^{\alpha-\alpha^{\prime}} L_{\mathrm{in}, S}^{\beta^{\prime}} L_{\mathrm{ex}, S}^{\beta-\beta^{\prime}} C_{S}^{\gamma} e^{h(t)}
$$

Similarly, we can obtain the knowledge absorption function for the core manufacture:

$$
K_{\text {Couple }}(M)=K_{S}^{\alpha_{1}^{\prime}} \operatorname{Couple}_{s}^{\alpha_{1}-\alpha_{1}^{\prime}} L_{\mathrm{in}, M}^{\beta_{1}^{\prime}} L_{\mathrm{ex}, M}^{\beta_{1}-\beta_{1}^{\prime}} C_{M}^{\gamma_{1}} e^{h(t)} .
$$

Then, submitting equation (3) into equation (6), the updated knowledge absorption function of the core manufacture can be written as

$$
K_{\text {Couple }}(M)=K_{S}^{2 \alpha_{1}^{\prime}-\alpha} \delta K_{M}^{\alpha_{1}-\alpha_{1}^{\prime}} L_{\mathrm{in}, M}^{\beta_{1}^{\prime}} L_{\mathrm{ex}, M}^{\beta_{1}-\beta_{1}^{\prime}} C_{M}^{\gamma_{1}} e^{h(t)}
$$

where $K_{\text {couple }}(S)$ and $K_{\text {couple }}(M)$ denote the absorbed knowledge for the cooperative firms. Let $\alpha$ l and $\alpha_{1}^{\prime}$ be the proportion of the redundant knowledge for each firm, and $\alpha-\alpha^{\prime}$ and $\alpha_{1}-\alpha_{1}^{\prime}$ can be denoted as the proportion of the desired coupling knowledge. Meanwhile, let $\beta^{\prime}$ and $\beta_{1}^{\prime}$ be the amount of internal knowledge integrated by the firms, so $\beta-\beta^{\prime}$ and $\beta_{1}-$ $\beta_{1}^{\prime}$ can be denoted as the amount of external knowledge integrated by the firms. What's more, let $\gamma$ and $\gamma_{1}$ be the proportion of the intellectual capital represented in the firms' total output. All of the parameters mentioned above in each sentence are represented by corresponding variables for the core manufacturer and the periphery suppliers. Moreover, $e^{h(t)}$ denotes the evolution of the cooperation cycle.

(2) Knowledge conversion:

Knowledge conversion is an important part in the first stage of knowledge collaboration, which is focused on the external knowledge being transferred into some required knowledge by the counterparty ones by activating the combination of the original internal knowledge with the external knowledge from outside and thereby increasing the added value on the whole. Therefore, integrating the abovementioned two parts in the first stage of knowledge collaboration, per-unit time knowledge transformation rate of the core manufacturer can be calculated as

$$
\begin{array}{r}
\dot{K}_{\text {Couple }}(M)=B\left[K_{S}^{2 \alpha_{1}^{\prime}}-\alpha_{1} \delta K_{M}^{\alpha_{1}-\alpha_{1}^{\prime}}\right]^{\theta}\left[L_{\mathrm{in}, M}^{\beta_{1}^{\prime}} L_{\mathrm{ex}, M}^{\beta_{1}-\beta_{1}^{\prime}}\right]^{\chi}\left[C_{M}^{\gamma_{1}}\right]^{\phi} e^{h(t)}, \\
\text { where } \phi \geq 0, \chi \geq 0, B>0 .
\end{array}
$$

Similarly, per-unit time knowledge transformation rate of the periphery suppliers can be calculated as

$$
\begin{array}{r}
\dot{K}_{\text {Couple }}(S)=A\left[K_{M}^{2 \alpha^{\prime}-\alpha} \delta K_{S}^{\alpha-\alpha^{\prime}}\right]^{\theta^{\prime}}\left[L_{\mathrm{in}, S}^{\beta^{\prime}} L_{\mathrm{ex}, S}^{\beta-\beta^{\prime}}\right]^{\chi^{\prime}}\left[C_{S}^{\gamma}\right]^{\phi^{\prime}} e^{h(t)}, \\
\text { where } \phi^{\prime} \geq 0, \chi^{\prime} \geq 0, A>0 .
\end{array}
$$

Specifically, in the above functions, $B$ and $A$ are the parameters of the firms' knowledge conversion. The parameters $\theta, \chi$, and $\phi$ represent the core manufacturer' return from the knowledge coupling, the human labour, and capital investment, respectively, in the knowledge collaboration, while $\theta^{\prime}$, $\chi^{\prime}$, and $\phi^{\prime}$ represent the corresponding periphery suppliers' parameters for the abovementioned on the core manufacturer.

\subsubsection{Knowledge Integration Stage in Interfirm Cooperation.} Following the first stage of knowledge collaboration, the knowledge integration stage mainly focuses on how the cooperation among the firms influences the output of the cooperation subjectively, since there should be the probability that the firms may conduct the knowledge rent-seek behaviour for their exclusive property of the knowledge, which could maximize private benefits. Therefore, the abovementioned statement is to be assumed in this paper, and it is sometimes the fact to some extent.

Regardless of what the knowledge category is, firms must have undergone many trials and errors in efforts to integrate the overall relevant knowledge, thereby incurring acquisition costs. Thus, let $v_{M}$ and $v_{S}$ be the cost coefficient of the knowledge conversion by the core manufacturer and the periphery suppliers, respectively, so that the expected return of the core manufacturer can be written as

$$
f\left(K_{M}\right)=K_{\text {Couple }}(M)+\dot{K}_{\text {Couple }}(M)-K_{M} v_{M} .
$$

Similarly, we can obtain the expected return of suppliers as follows:

$$
f\left(K_{S}\right)=K_{\text {Couple }}(S)+\dot{K}_{\text {Couple }}(S)-K_{S} v_{S} .
$$

Then, we can obtain the expected return of the cooperation system and the return function can be drawn on the condition that there should be a cooperation among the firms when $\left(f\left(K_{S}\right) / f\left(K_{R, S}\right)\right)>1$. On the above analysis, the 
expected return function of the whole system should be calculated as

$$
f\left(K_{M}, K_{S}\right)=f\left(K_{M}\right)+f\left(K_{S}\right)+\xi f\left(K_{M}, K_{S}\right)+f\left(K_{R, S}\right),
$$

where $\xi f\left(K_{M}, K_{S}\right)$ represents the cobenefits of the cooperation system, and $f\left(K_{R, S}\right)$ denotes the benefits from the rent-seeking. In most cases, the benefits from the rentseeking always are obtained by the core manufacture. Therefore, the utility function can be used to describe the specific form of $f\left(K_{R, S}\right)$ so that it can be defined as follows:

$$
\begin{aligned}
f\left(K_{R, S}\right)= & {\left[1-p\left(K_{R, S}\right)\right] f\left[K_{S}\left(f\left(K_{R, S}\right)\right)\right] } \\
& +p\left(K_{R, S}\right) \tau\left(K_{R, S}\right) f\left[K_{S}\left(f\left(K_{R, S}\right)\right)\right] .
\end{aligned}
$$

Combining equation (13) with equation (14), we can obtain the transformation of the above equation:

$$
\begin{aligned}
f\left(K_{M}, K_{S}\right)= & f\left(K_{M}\right)+f\left(K_{S}\right)+\zeta f\left(K_{M}, K_{S}\right) \\
& +\left[1-p\left(K_{R, S}\right)+p\left(K_{R, S}\right) \tau\left(K_{R, S}\right)\right] \\
& \cdot f\left[K_{S}\left(f\left(K_{R, S}\right)\right)\right],
\end{aligned}
$$

where $p\left(K_{R, S}\right)$ denotes the probability of knowledge rentseeking behaviour, and $\tau\left(K_{R, S}\right)$ denotes the disciplinary function over the knowledge rent-seeking behaviour. Moreover, the assumption of expression $\tau\left(K_{R, S}\right)<0$ and $\tau \prime\left(K_{R, S}\right)<0$ means that the higher the expected return is, the greater the punishment obtained for rent-seeking. Specifically, it is assumed that the probability $p\left(K_{R, S}\right)$ increases as $f\left(K_{R, S}\right)$ increases when the two firms belong to complementary industry, while in the competitive industry, the participants' willingness should be motivated to a large extent by a situation in which $p\left(K_{R, S}\right)$ has opposite evolving orbit as $f\left(K_{R, S}\right)$ goes, where $p^{\prime}\left(K_{R, S}\right)>0$ and $p^{\prime \prime}\left(K_{R, S}\right)<0$.

What's more, although $\zeta f\left(K_{M}, K_{S}\right) \geq 0$, the uncertainty of expected return in cooperation will lead to the decrease of that return and could exert an external force on stability of the whole system. Therefore, we can obtain the following results:

(1) If $1-p\left(K_{R, S}\right)+p\left(K_{R, S}\right) \tau\left(K_{R, S}\right) \leq 0, f\left(K_{R, S}\right)$ is negative, the periphery suppliers will not conduct knowledge rent-seeking behaviour;

(2) If $1-p\left(K_{R, S}\right)+p\left(K_{R, S}\right) \tau\left(K_{R, S}\right)>0, f\left(K_{R, S}\right)$ is positive, the periphery suppliers could obtain the maximum rent-seeking benefit $K_{R, S}^{*}$ (see expression (15)), which is dominated by the disciplinary function.

$$
\begin{aligned}
K_{R, S}^{*} & =\frac{\partial\left[f\left(K_{S}\right)+F\left(K_{R, S}\right)\right]}{\partial K_{R, S}} \\
& =f\left[p\left(K_{R, S}\right), \tau\left(K_{R, S}\right), f\left(K_{S}\right)\right] .
\end{aligned}
$$

In expression (15), it is the equilibrium return of the system in cooperation, not the best profit point for suppliers, and they would like to prefer participating with the counterparties to maximize their profits. Therefore, there should be a critical value for the parameter $\eta$ for refusing the rent-seeking, which can be implemented with some incentive strategies by the core manufacture on the expected return for the whole cooperation system, so as to maintain the effective cooperation. Based on the abovementioned analysis, when $\left(\left(f\left(K_{S}\right)\right) /\left(f\left(k_{R, S}^{*}\right)\right)\right)=\left(\left(f\left(K_{S}\right)\right) /([1-p\right.$ $\left.\left.\left.\left(k_{R, S}^{*}\right) \tau\left(k_{R, S}^{*}\right)\right] f\left[K_{S}\left(f\left(K_{R, S}^{*}\right)\right)\right]\right)\right) \geq \eta$, the suppliers will refuse to choose rent-seeking behaviour, and we can obtain the following equation:

$$
K_{S}^{*}=g\left[p\left(K_{R, S}^{*}\right), \tau\left(K_{R, S}^{*}\right), f\left[K_{S}\left(f\left(K_{R, S}^{*}\right)\right)\right]\right],
$$

where $K_{S}^{*}$ denotes the periphery supplier' critical knowledge point for the effective cooperation. When $K_{S}^{*} \geq K_{R, S}^{*}$, it is fair for both the participators in the cooperation system. However, $K_{S}$ has an upper bound $J$, but $K_{R, S}$ does not. Therefore, in order to make sure the cooperation system goes well, it is required that the expression $p\left[g^{-1}(J)\right]>p\left(K_{R, S}^{*}\right)$ or $p^{-1}\left[g^{-1}(J)\right] \longrightarrow \infty$ is fulfilled, which means that providing adequate knowledge needed so as to lead to denying rent-seeking behaviour.

\subsubsection{Knowledge Interaction Stage in Interfirm Cooperation.}

The knowledge interaction stage is the last stage in the process of knowledge collaboration, which mostly focuses on how the cooperation system is going on when the former tow stages of knowledge collaboration between the two types of firms are manipulated. The cooperation system based on knowledge evolves nonlinearly and the output of the cooperation depends on various complex factors both subjectively and objectively.

In order to assess the fluctuation effect of the cooperation system on knowledge interaction between firms, we combine the knowledge potential among the firms with their expected return through nonlinear methods. Therefore, it is expected that the stability of the innovation system can be maintained by the participators' self-adjustments and the external regulations or related parameters.

Therefore, assuming certain expected return of the core manufacturer, we define the suppliers' knowledge input $\alpha_{1}$ and the knowledge integration capability $\beta$ as the ordinal variables of the system. According to the model proposed by Haken [66], the impact from these parameters on the evolution of the interfirm cooperation system can be presented as follows:

$$
\begin{gathered}
\dot{\beta}=-\chi^{\prime} \beta-\gamma \beta \alpha_{1}, \\
\dot{\alpha}_{1}=-\theta^{\prime} \alpha_{1}-\phi^{\prime} \beta^{2} .
\end{gathered}
$$

In the above equation, placing a restriction on the firms' level of knowledge integration capability and its knowledge input, the labour return to scale $\chi^{\prime}$ and the return to scale of the needed knowledge $\theta^{\prime}$ are selected as the damping coefficients of the system. The capital investment index $\gamma$ and the innovation capital return to scale $\phi^{\prime}$ are the interaction strength coefficients between the two state variables $\alpha_{1}$ and $\beta$. 
Based on the above definition, a stationary solution for the system is $\alpha_{1}=\beta=0$, where $\theta^{\prime} \geq\left|\chi^{\prime}\right|, \chi^{\prime}>0$. Let $\alpha_{1} \approx 0$ and integrate it into equation (18), we then have

$$
\alpha_{1}(t) \approx \frac{\phi^{\prime}}{\theta^{\prime}} \beta^{2}(t)
$$

Submitting the return from equation (19) into equation (17), we can obtain the ordered parameter and the evolution trajectory of the system as the following equation, which can be seen in Figures 2 and 3.

$$
\begin{aligned}
& \dot{\beta}=-\chi^{\prime} \beta-\frac{\gamma \phi^{\prime}}{\theta^{\prime}} \beta^{3}, \\
& V=0.5 \chi^{\prime} \beta^{2}+\frac{\gamma \phi^{\prime}}{4 \theta^{\prime}} \beta^{4} .
\end{aligned}
$$

In Figure 3 , it can be seen that $\alpha_{1}$ is decided by $\beta$. If the control variable causes the system to pass the instability point, $\beta$ will adjust the system to a new ordered structure through its dominant ability. According to the evolution trajectory of the system in Figure 3, we can find that the knowledge base and integration capability can contribute to the nonlinear evolution of the system in three varying scales through each firm's mutual coordination.

\section{Evolutionary Model of Interfirm Cooperation for Radical Innovation}

Based on the abovementioned analysis about the framework of interfirm cooperation on knowledge collaboration, an evolutionary model of the interfirm cooperation for radical innovation will be constructed. Considering that the interfirm cooperation should be simply seen as a series of interactions among the firms in some industry chain, and the emerging innovation should be roughly seen as a set of output performance from the complex interactions, the theory of vibration mechanics, which is originated from the science of physics, is applied to model the interfirm cooperation system in complex science so as to explore how the system evolves dynamically and track the possible innovation performance.

3.1. Presupposition and Assumption. To start with, some presuppositions and assumptions for the modelling should be proposed. Since the interfirm cooperation comes among the firms in some certain industries, it is assumed that a core firm and its suppliers be considered as the coupling vibrators in the cooperation system, which means that the possible innovation for the industry comes from the cooperation among the firms in a reverse chain. According to the vibration theory and the mechanism of the interfirm cooperation, the objective factor of knowledge potential among the firms and the subjective factor of knowing rent-seeking behaviour on the cooperation system are quantified and analysed to check how the outcome of the cooperation system varies.
Therefore, three types of scenarios about the knowledge potential, which is an important objective factor influencing the cooperation, could be clarified as follows:

(1) Assuming a scenario, where $\xi \in(0,1)$, means that there is a relatively low knowledge potential difference between the firms, and the knowledge absorption and transformation could be completely and effectively conducted.

(2) Assuming a scenario, where $\xi \longrightarrow\{1\}$, means that there is a critical knowledge potential difference between the firms and the shared knowledge itself could be convergent among the participants in the cooperation system.

(3) Assuming a scenario, where $\xi \in(1,+\infty)$, means that there is a relatively high knowledge potential difference between the firms, and knowledge absorption and conversion could be utterly hindered.

Moreover, two distinct situations for the analysis on the modelling and the simulation are generated over the subjective factors. On the one hand, the first situation without knowledge rent-seeking behaviour can be generated as $p\left(K_{R, S}\right)=0$; On the other hand, the second situation with a different probability of knowledge rent-seeking behaviour can be generated as $p\left(K_{R, S}\right) \in(0,1)$.

\subsection{Modelling and Analytical Analysis}

3.2.1. Cooperation without Knowledge Rent-Seeking Behaviour. Applying the vibration theory and method into the interfirm cooperation on knowledge collaboration, we can obtain the dynamical interfirm cooperation effect evolution equation as follows:

$$
\gamma \frac{\partial^{2} f}{\partial t^{2}}+\beta \frac{\mathrm{d} f}{\mathrm{~d} t}+\alpha_{1} f=0,
$$

where $\alpha_{1}, \beta$, and $\gamma$ denote the elasticity index of knowledge input level, knowledge integration capability, and the capital input level from periphery suppliers, respectively. Besides, $\partial^{2} f / \partial t^{2}$ denotes the changing frequency of the system's expected return, and $\mathrm{d} f / \mathrm{d} t$ denotes the expected return rate of the system.

Based on the above definition, we need to transform the above equation with the frequency parameters. Let $\omega$ be the ratio of the suppliers' knowledge input to the capital input, we then can obtain the following expression:

$$
\omega^{2}=\frac{\alpha_{1}}{\gamma} \text {. }
$$

Meanwhile, introducing the dimensionless parameter $\xi=(\beta / 2 \gamma \omega)$ and submitting it with equation (22) into equation (21), we can rewrite equation (21) as follows:

$$
\frac{\partial^{2} f}{\partial t^{2}}+2 \xi \omega \frac{\mathrm{d} f}{\mathrm{~d} t}+\omega^{2} f=0
$$

Finally, expected return of the system, represented as the cooperation effect, can be transformed as 


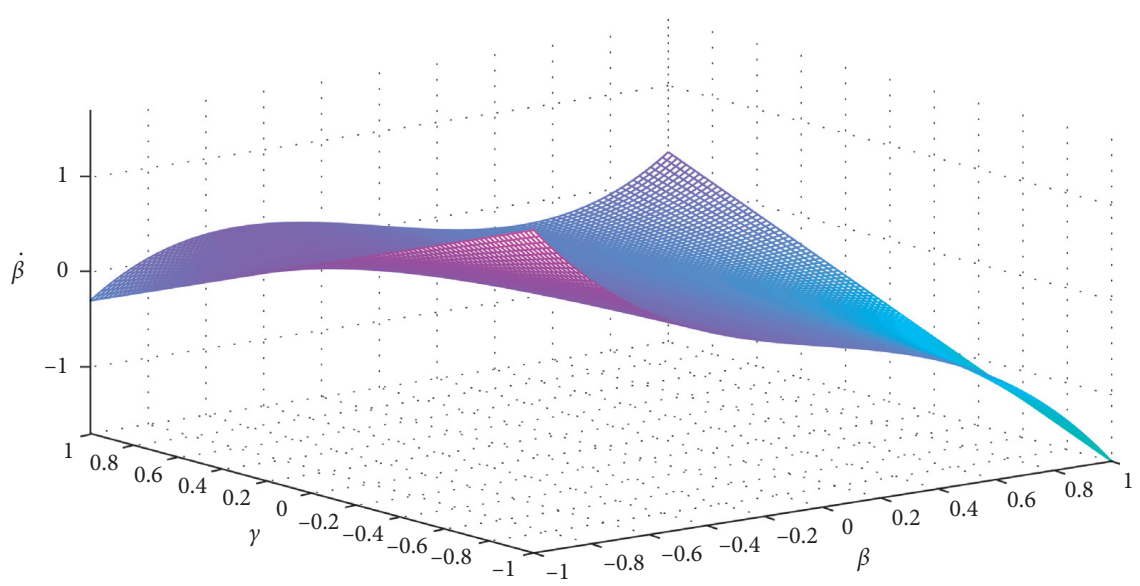

(a)

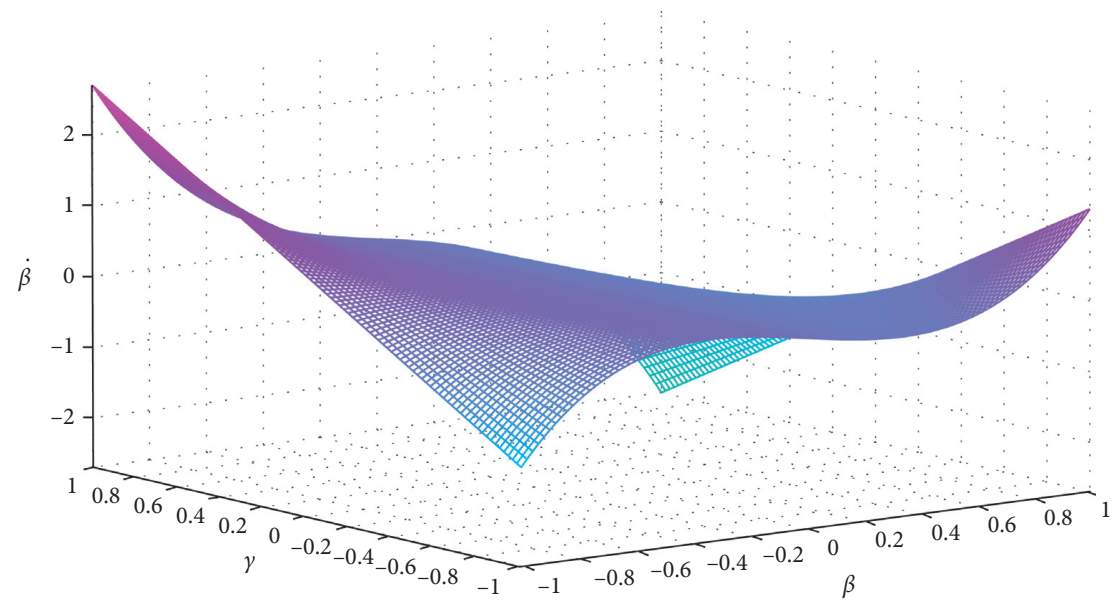

(b)

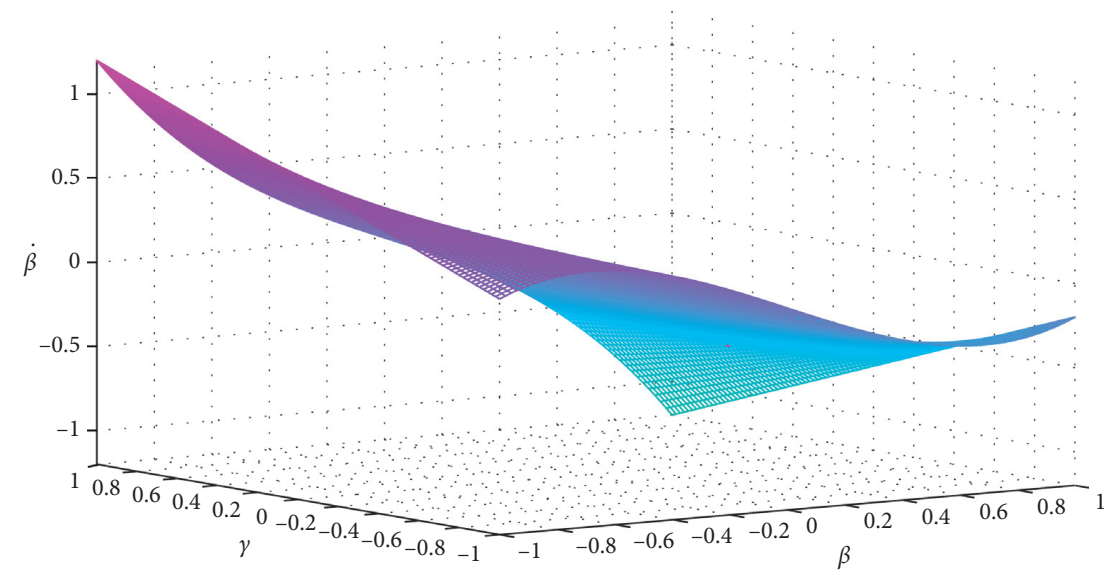

(c)

Figure 2: Ordered structure of the system by $\dot{\beta}$. (a) Decreasing returns to scale. (b) Increasing returns to scale. (c) Constant returns to scale. Note. The returns to scale values are set as $0.8,1.3$, and 1 , where $\chi^{\prime}=0.7$ and $\phi \prime=0.2$.

$$
f(t)=c_{1} e^{\left(-\xi \omega+\omega \sqrt{\xi^{2}-1}\right) t}+c_{2} e^{\left(-\xi \omega-\omega \sqrt{\xi^{2}-1}\right) t}
$$

It is straightforward to show that the utility brought by the knowledge collaboration is decided by $\xi$. Hence, the system's expected return that exhibits stability equilibrium, a divergence, or a periodic profit fluctuation is fluctuated by knowledge potential difference. Besides, since there are three classified scenarios over knowledge potential difference, analysis on the modelling and its evolvement can be conducted in the below sectors.

(1) Scenarios with high knowledge potential difference among firms: 


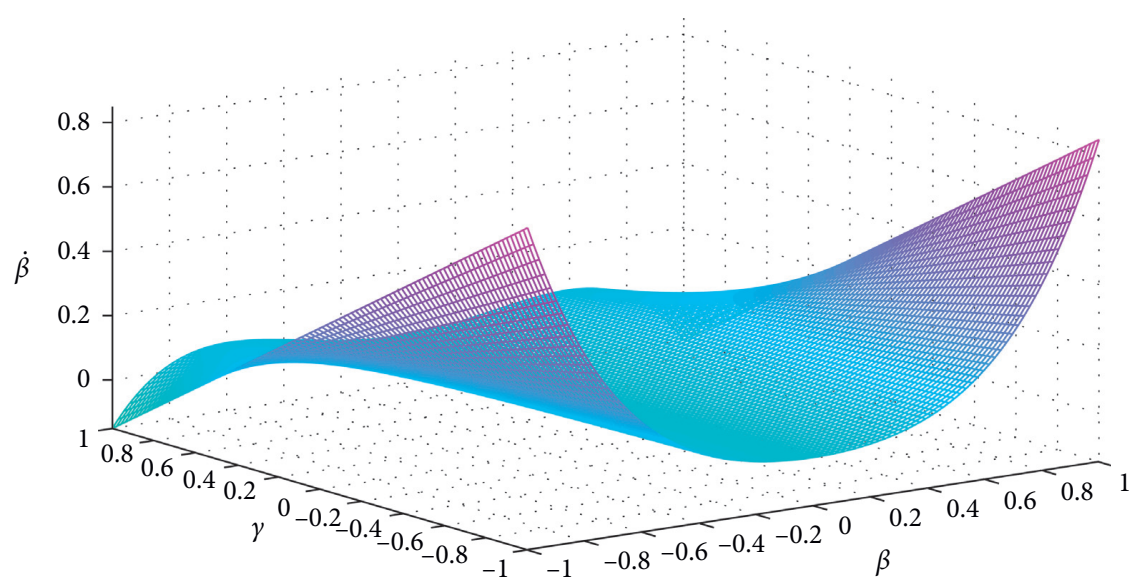

(a)

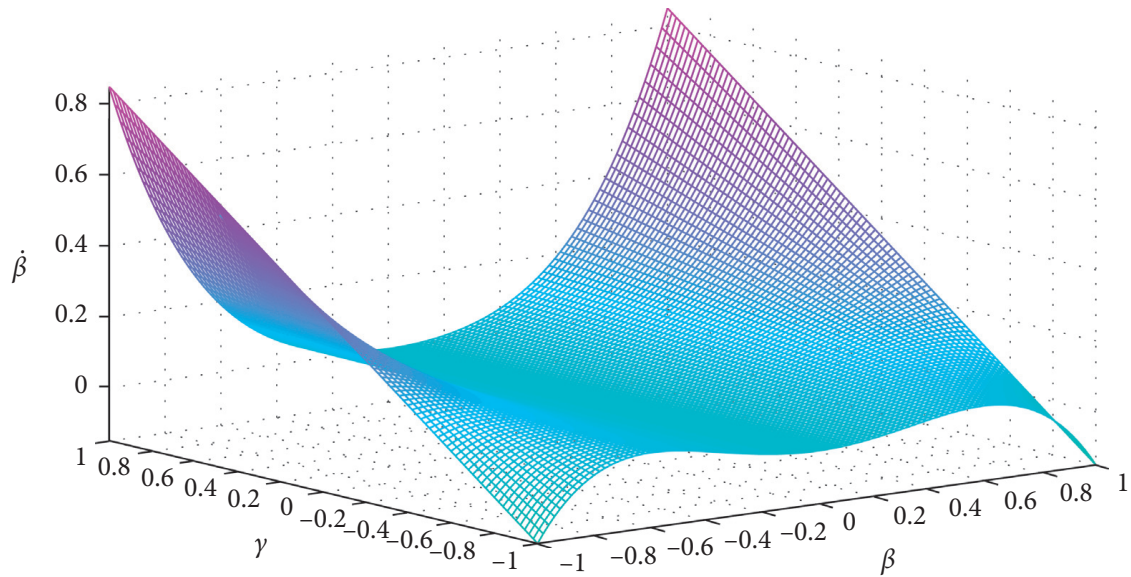

(b)

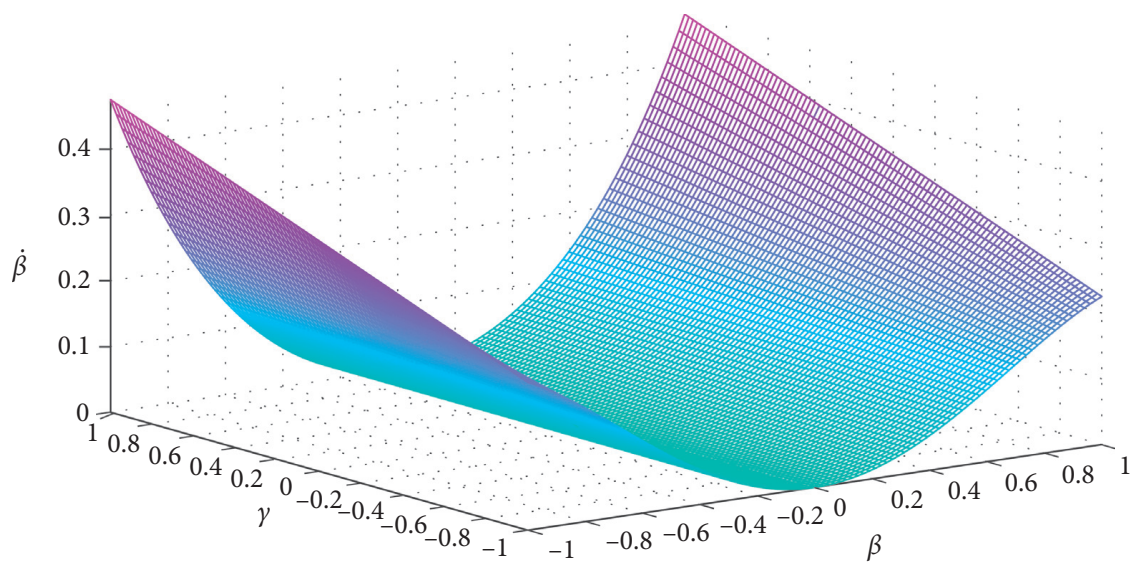

(c)

FiguRe 3: Evolution trajectory of the system by $V$. (a) Decreasing returns to scale. (b) Increasing returns to scale. (c) Constant returns to scale. Note. The returns to scale values are set as $0.8,1.3$, and 1 , where $\chi^{\prime}=0.7$ and $\phi \prime=0.2$.

Based on the abovementioned model, when $\xi \in(1,+\infty)$, the ability of internal automatic adjustment can be enhanced in the cooperation system according to the vibrator theory in Physics. Thus, if the periphery firms have a lower knowledge integration capability, the impact on the evolution trajectory of the cooperation effect from the negative factor $\beta$ in the system is much more than that from 
the positive factor $\alpha_{1}$. From this, we can obtain the expected return of the system as follows:

$$
\begin{aligned}
& c_{1}=\frac{1}{2}\left(f_{0}+\frac{\left(\mathrm{d} f_{0} / \mathrm{d} t\right)+\xi \omega f_{0}}{\omega \sqrt{\xi^{2}-1}}\right), \\
& c_{2}=\frac{1}{2}\left(f_{0}-\frac{\left(\mathrm{d} f_{0} / \mathrm{d} t\right)+\xi \omega f_{0}}{\omega \sqrt{\xi^{2}-1}}\right) .
\end{aligned}
$$

From this, the parameter $\xi$ gives some critical implications. On one hand, if the potential difference exceeds a certain threshold, it will hinder knowledge conversion. On the other hand, if the periphery firms have strong capabilities in knowledge absorption and integration, they will achieve a greater potential leap and facilitate radical innovation cooperation.

(2) Scenarios with low knowledge potential difference among firms:

When $\xi<1$, some periphery firms should be afraid of being replaced by their counterparty competitors, and the competition within the system will be much fiercer. Therefore, the performance of the cooperation system has periodic fluctuations in short term, and its frequency of fluctuations is relatively faster. However, as the system can automatically self-adjust in certain conditions, therefore the long-term cooperation effect remains stable.

Based on the above analysis and equation (24), the system's expected return is given by

$$
f(t)=e^{-\xi \omega_{1} t} A \sin \left(\omega_{r}+\alpha\right),
$$

where $A$ denotes the amplitude of the system's maximum expected return and $\omega_{\gamma}$ denotes the frequency of the system's expected return, still affected by $\xi$. In addition, the fluctuation frequency of the innovation marginal revenue is smaller than the intensity changing frequency $\omega$ of the knowledge input by the periphery firms. Therefore, the frequency of total earnings volatility can be set up as

$$
\omega_{r}=\omega \sqrt{1-\xi^{2}}
$$

(3) Scenarios with the critical knowledge potential difference among firms:

When $\xi \longrightarrow\{1\}$, the core manufacturer's dominant advantage in the cooperation system will be weakened, possibly resulting in an increasing cost of cooperation and hindering cooperation efficiency. Therefore, combining with equation (24), we can obtain the total expected return in a stable state:

$$
f=\left[f_{0}(1+\omega t)+\frac{\mathrm{d} f_{0}}{\mathrm{~d} t} t\right] e^{-\omega, t} .
$$

3.2.2. Cooperation with Knowledge Rent-Seeking Behaviour. If the probability of the suppliers' rent-seeking behaviour is continuous with a certain knowledge potential difference, the core manufacturer could have enough motivation to cooperate with the suppliers to seek the maximum profits from the cooperation, especially when there is obvious product relevance and the knowledge value $p^{-1}\left(K_{R, S}^{*}\right)<$ $p^{-1}\left(K_{S}^{*}\right)$. Therefore, we can rebuild the dynamical fluctuation equation of the system by adopting the theory of vibration mechanics:

$$
\gamma \frac{\partial^{2} f}{\partial t^{2}}+\beta \frac{\mathrm{d} f}{\mathrm{~d} t}+\alpha_{1} f=p\left(K_{R, S}\right) \sin \theta^{*} t .
$$

Submitting equation (22) and the parameter $\xi$ into equation (29), we can obtain the following equation:

$$
\frac{\partial^{2} f}{\partial t^{2}}+2 \xi \omega \frac{\mathrm{d} f}{\mathrm{~d} t}+\omega^{2} f=\frac{p\left(K_{R, S}\right)}{\gamma} \sin \theta^{*} t .
$$

Therefore, the dynamical evolution equation of the total expected return of the system can be shown as

$$
\begin{aligned}
f= & e^{-\xi \omega t}\left(\frac{\left(\mathrm{d} f_{0} / \mathrm{d} t\right)+\xi \omega f_{0}}{\omega_{\gamma}} \sin \omega_{\gamma} t+f_{0} \cos \omega_{\gamma} t\right) \\
& +A e^{-\xi \omega t}\left(\frac{\xi \omega \sin \alpha-\theta \cos \alpha}{\omega_{\gamma}} \sin \omega_{\gamma} t+\sin \alpha \cos \omega_{\gamma} t\right. \\
& \left.+\sin \alpha \cos \omega_{\gamma} t\right) \\
& +A \sin \left(\theta^{*} t-\alpha\right) .
\end{aligned}
$$

Concerning equation (31), parts on the right-hand side of the equation represents the influence on the volatility of the total expected return from different factors, which are the suppliers' knowledge input level and the core manufacture's incentives, which are proposed to motivate suppliers to increase the knowledge input rather than to choose rent-seeking behaviour and the incentive level $\theta^{*}$ in the long-term stable state, respectively.

According to the abovementioned analysis, due to the knowledge potential difference and rent-seeking behaviour, the efficiency of the knowledge conversion decreases as time goes by. At last, it can evolve into a stable equilibrium, which can be depicted as

$$
f=A \sin \left(\theta^{*} t-\alpha\right) .
$$

Moreover, if the system evolves into the final stable state, the peak of the incentive intensity by the core manufacturer can be shown as

$$
\begin{aligned}
& A=\zeta f_{s t}, \\
& \alpha=\arctan \frac{2 \xi \eta}{1-\eta^{2}},
\end{aligned}
$$


where $\zeta$ denotes the systems' synergistic expected return, which quantifies the relationship between the changing frequency of the incentive degree $\theta^{*}$ and the system's expected return $\omega_{\gamma}$. Note that $\eta$ represents the impact on the total expected return of the system from the incentive by the core manufacturer; this impact can be calculated as the proportion of the periphery suppliers' changing frequency of rent-seeking behaviour $\theta^{*}$ to the changing frequency of the total expected return $\omega_{\gamma}$ presented as follows:

$$
\eta=\frac{\theta^{*}}{\omega_{\gamma}} .
$$

Thus, by integrating equations (22) and (34), we can obtain that

$$
\zeta=\frac{1}{\sqrt{\left(1-\eta^{2}\right)^{2}+(2 \xi \eta)^{2}}} .
$$

Overall, combining equation (31) with equation (33), the dynamic evolution of the synergistic expected return of the cooperation system, where the suppliers are faced with the same incentive but with a different knowledge potential, can be obtained:

$$
f\left(\zeta f\left(K_{M}, K_{S}\right)\right)=\frac{f_{s t}}{2 \xi}\left[e^{-\xi \omega t}\left(\frac{\xi \omega}{\omega_{\gamma}} \sin \omega_{\gamma} t+\cos \omega_{\gamma} t\right)-\cos \omega t\right] .
$$

\section{Simulation Analysis}

Based on the above modelling and analytical analysis over the interfirm cooperation from the perspective of knowledge collaboration, simulation analysis is conducted in this section so as to explore the dynamical evolving features of the interfirm cooperation system and how the related factors impact the evolving process. For simplicity, the experiment is conducted based on the following conditions: on one hand, if the cooperation system is mainly dominated by the core manufacturer, the periphery supplier firms will be eager to achieve the goal of maximizing their total expected return so that the system is supposed to be solidly stable. On the other hand, if the cooperation system is in a noncooperative state, each firm should maximize its own expected return. Moreover, the related parameters for the simulation experiment are shown in Table 1.

To start with, let the initial short-term profit level of the core manufacturer be the initial state of the cooperation system revenue and let the periphery firms' initial profit level be the initial value of the variables for the evolution of system, then the simulation experiment will be conducted. What's more, both the subjective and objective dimensions are considered in the model, represented by the condition with knowledge rent-seeking behaviour and with knowledge potential difference, respectively. Therefore, the simulation experiments are generated by the two dimensions to explore the evolution of the interfirm cooperation system.
4.1. Evolution of Interfirm Cooperation without Knowledge Rent-Seeking. In the scenario, without knowledge rentseeking, three different levels of the knowledge potential difference among firms are discussed, respectively.

(1) With high knowledge potential difference:

On the abovementioned setup of the parameters and the constructed model, the evolution trajectory of the total expected revenue under the condition of high knowledge potential difference can be obtained in Figure 4.

In Figure 4, we can observe that high knowledge potential difference has an unsustainable positive effect on the system's short-term expected return during $t \in\left(0, t^{*}\right)$, where $t^{*} \in(0,0.5)$, regardless of the periphery firms' initial state of profit or loss. Except for that, some other interesting results and conclusions can be drawn as follows. First, if suppliers have an initial profit, the expected return increases during $t \leq t^{*}$, and the maximum expected return can be obtained on $t=t^{*}$. Due to the negative effects from high knowledge potential, with the increasing of high knowledge potential difference, the total expected return of the system decreases until it reaches the stable state. Meanwhile, the total expected return increases as the suppliers' initial profit increases. When $t \geq t^{*}$, its volatility decreases as the suppliers' initial profit decreases. Second, if the suppliers have an initial loss, the expected return decreases during $t \in\left(0, t^{*}\right)$, and the minimum expected return can be obtained on $t=t^{*}$. The higher the suppliers' loss is, the lower the expected return is. However, high knowledge potential difference can reduce the degree of the system's expected return loss when $t \geq t^{*}$. Third, when $\dot{f}_{0}=0$, the expected return always decreases slowly in each sample. The higher the knowledge potential difference is, the lower the maximum value of expected return will be. However, when $\xi \in(3,5)$ and $f_{0}<0$, the system would always be profitable, and losses can be reduced with the increasing values of $\xi$.

What's more, it can be inferred from Figure 4 that the return fluctuation of the cooperation system in the short-term is larger than that in the medium- or long-term. The lower the $\xi$ is, the more the fluctuant intensity in the short-term is. With a high knowledge potential difference, the system has a long-term stable state after its automatic adjustment. Although the high knowledge potential difference reduces the system's initial profit and the system's maximum benefits, it ameliorates the negative effect of the suppliers' initial losses on the system's short-term expected return and minimizes the system's loss.

(2) With low knowledge potential difference:

Under the condition of low knowledge potential difference, the total expected revenue in the simulation experiment can be seen in Figure 5. In Figure 5(a), four types of initial profit rates with the 
TABLE 1: Parameters in the simulation experiment.

\begin{tabular}{|c|c|c|c|}
\hline Parameters & Value range & Meaning & Experiment conditions \\
\hline$\alpha_{1}$ & $\alpha_{1}>0$ & Index of periphery firms' knowledge input stock & \\
\hline$\beta$ & $\beta>0$ & Index of periphery firms' knowledge integration capability & \\
\hline$\gamma$ & $\gamma>0$ & Index of periphery firms' capital investment & \\
\hline$\omega$ & $0<\omega<1$ & $\begin{array}{c}\text { Proportion of periphery firms' knowledge input to capital } \\
\text { investment }\end{array}$ & $\omega^{2}=\left(\alpha_{1} / \gamma\right)$ \\
\hline & & & $\begin{array}{c}\xi \in(0,1) \text { means low knowledge potential } \\
\text { difference; }\end{array}$ \\
\hline$\xi$ & $\xi=(\beta / 2 \gamma \omega)>0$ & Dimensionless parameter & $\begin{array}{c}\xi \longrightarrow\{1\} \text { means critical knowledge potential } \\
\text { difference; }\end{array}$ \\
\hline & & & $\begin{array}{c}\xi \in(1,+\infty) \text { means high knowledge potential } \\
\text { difference. } \\
\dot{f}_{0}>0 \text { means initial short-term profit of } \\
\text { periphery firms; }\end{array}$ \\
\hline$f_{0}$ & & $\begin{array}{l}\text { Initial short-term expected return change rate of periphery } \\
\text { firms, indicating the initial contribution to the system }\end{array}$ & $\begin{array}{c}\dot{f}_{0}=0 \text { means periphery firms make no } \\
\text { different contribution to the initial short-term } \\
\text { of the system; } \\
\dot{f}_{0}<0 \text { means initial short-term losses of } \\
\text { periphery firms. }\end{array}$ \\
\hline $\mathrm{d} f / \mathrm{d} t$ & & Yield rate of the cooperation system & \\
\hline$\partial^{2} f / \partial t^{2}$ & & Changes in the frequency of the system's expected return & \\
\hline$\omega_{\gamma}$ & $0<\omega_{\gamma}<\omega$ & Frequency of the system's expected return & \\
\hline$\theta^{*}$ & & $\begin{array}{c}\text { Changes in the frequency of incentives to periphery firms } \\
\text { by core manufacture }\end{array}$ & $\begin{array}{l}\text { Periphery firms have rent-seeking behaviour } \\
\text { and the system is stable. }\end{array}$ \\
\hline$\eta$ & $\eta>0$ & $\begin{array}{l}\text { Ratio of change in the frequency of incentives of core } \\
\text { manufacturer to the frequency of change in the total } \\
\text { expected return of the system }\end{array}$ & $\begin{array}{c}\eta \longrightarrow 0 \text { means that core manufacturer takes } \\
\text { preincentives; } \\
\eta \longrightarrow \infty \text { means that core manufacturer takes } \\
\text { ex-postincentives; } \\
\eta \longrightarrow 1 \text { means that core manufacturer takes } \\
\text { the in-process incentives. }\end{array}$ \\
\hline
\end{tabular}

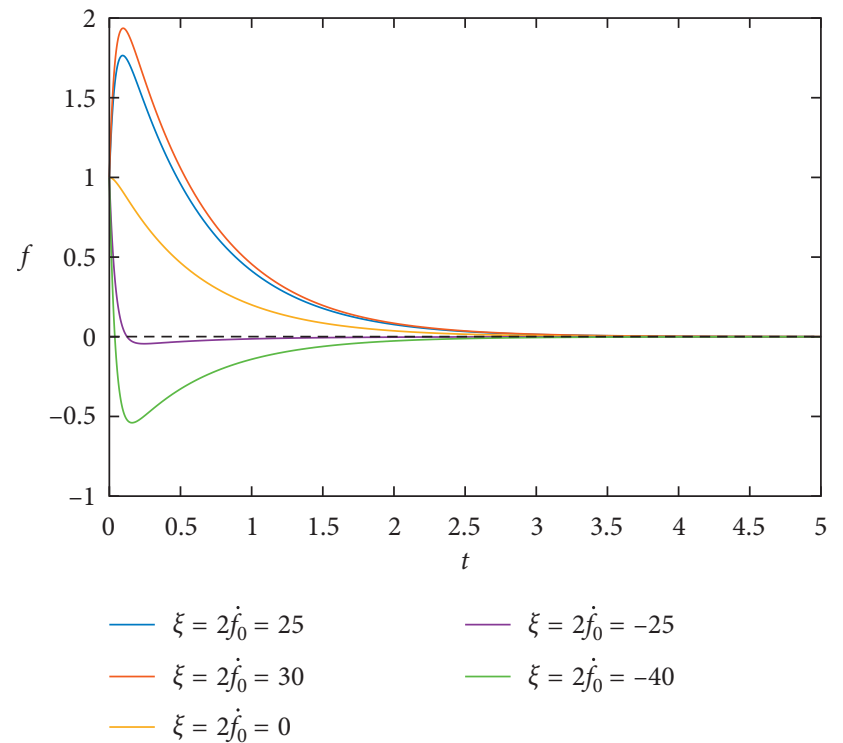

(a)

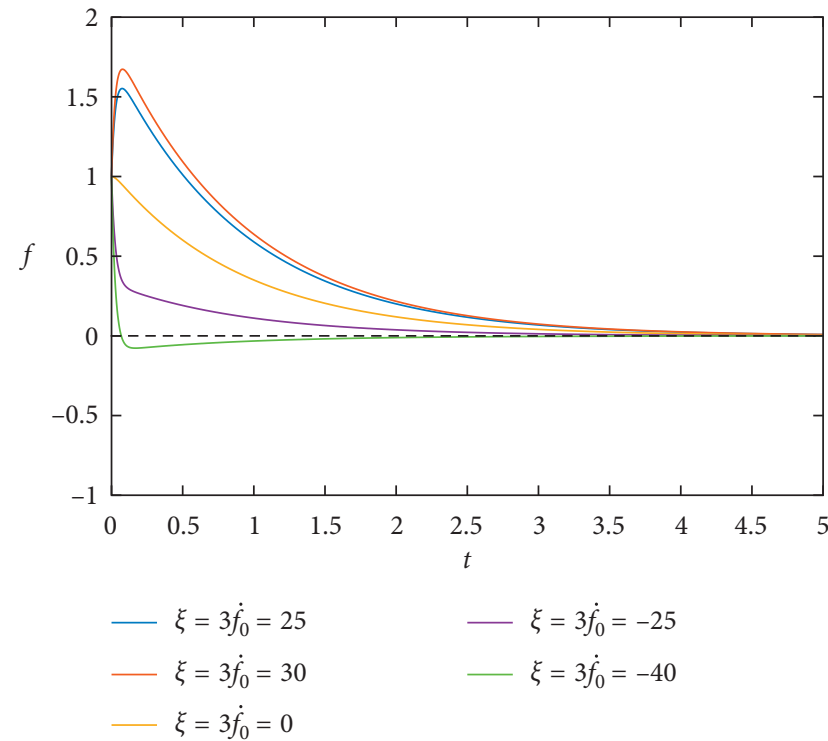

(b)

Figure 4: Continued. 


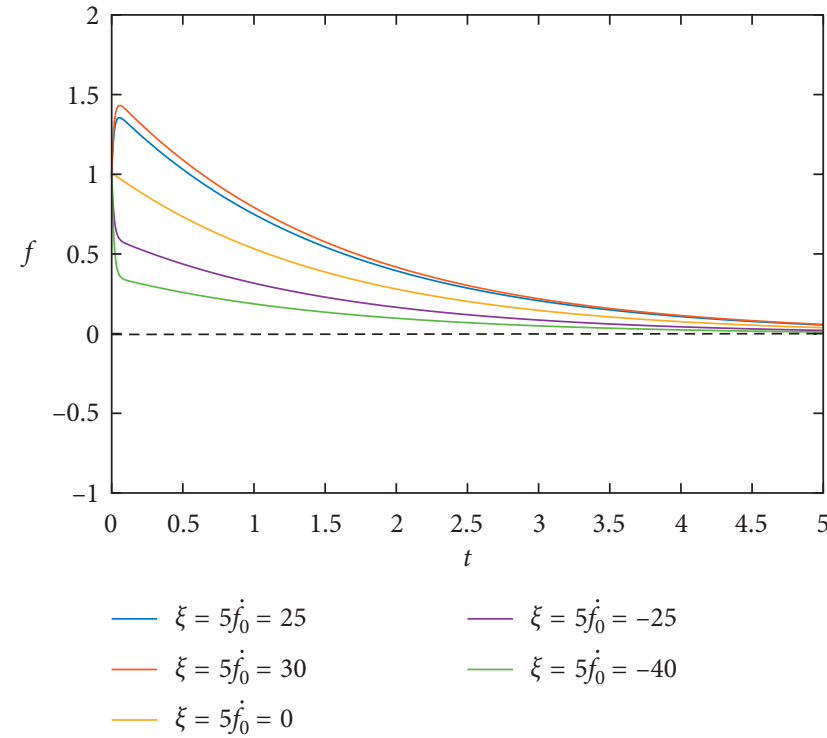

(c)

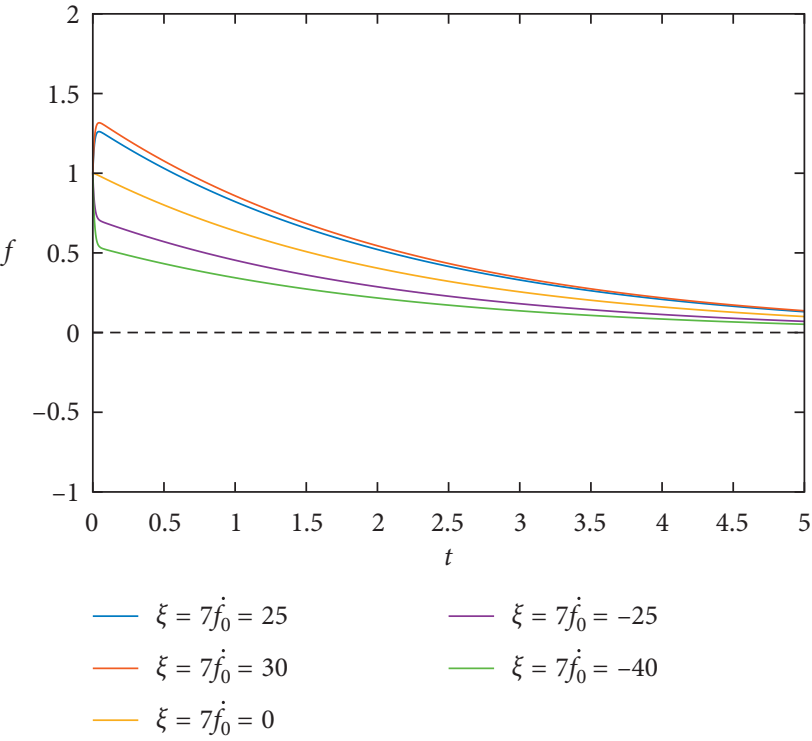

(d)

Figure 4: Impact on evolution of the cooperation system under high knowledge potential difference. Note. Value of the parameters is selected as follows: four different values of high knowledge potential difference are set up as $\xi=2,3,5,7$. The initial profit rates of periphery firms are set up as $\dot{f}_{0}=25,30$. The initial loss rates are set up as $\dot{f}_{0}=-25,-40$. The initial default variable is set up as $\dot{f}_{0}=0$. The horizontal axis denotes the time steps, and the vertical axis denotes the expected return of the system.
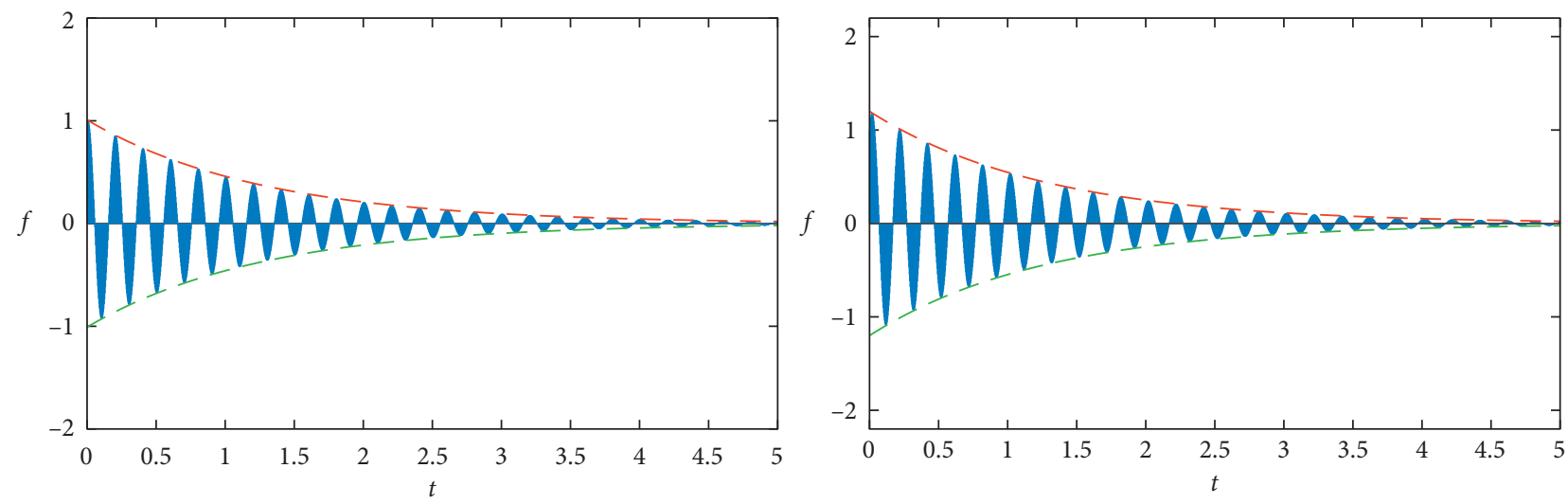

$\xi=0.025, \dot{f_{0}}=5$

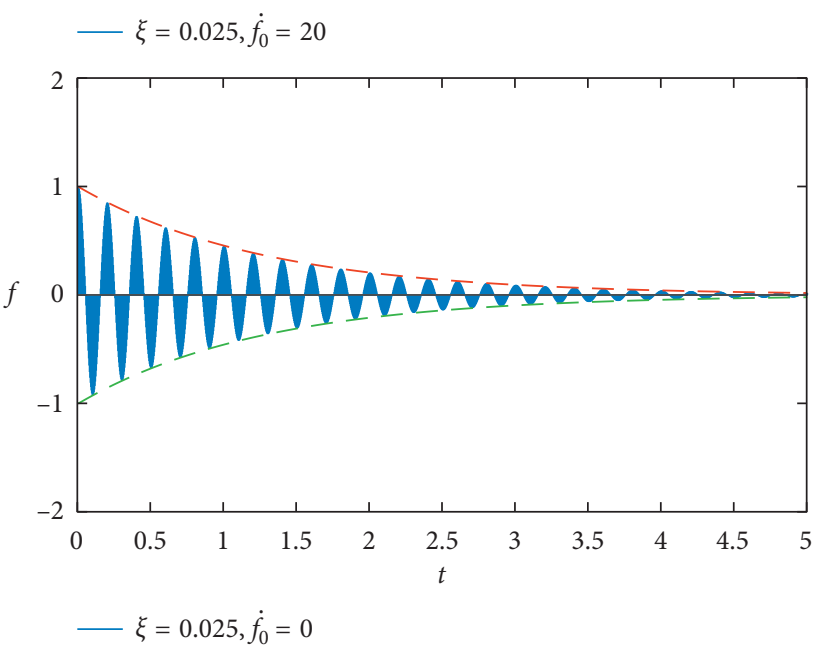

(a)

Figure 5: Continued. 

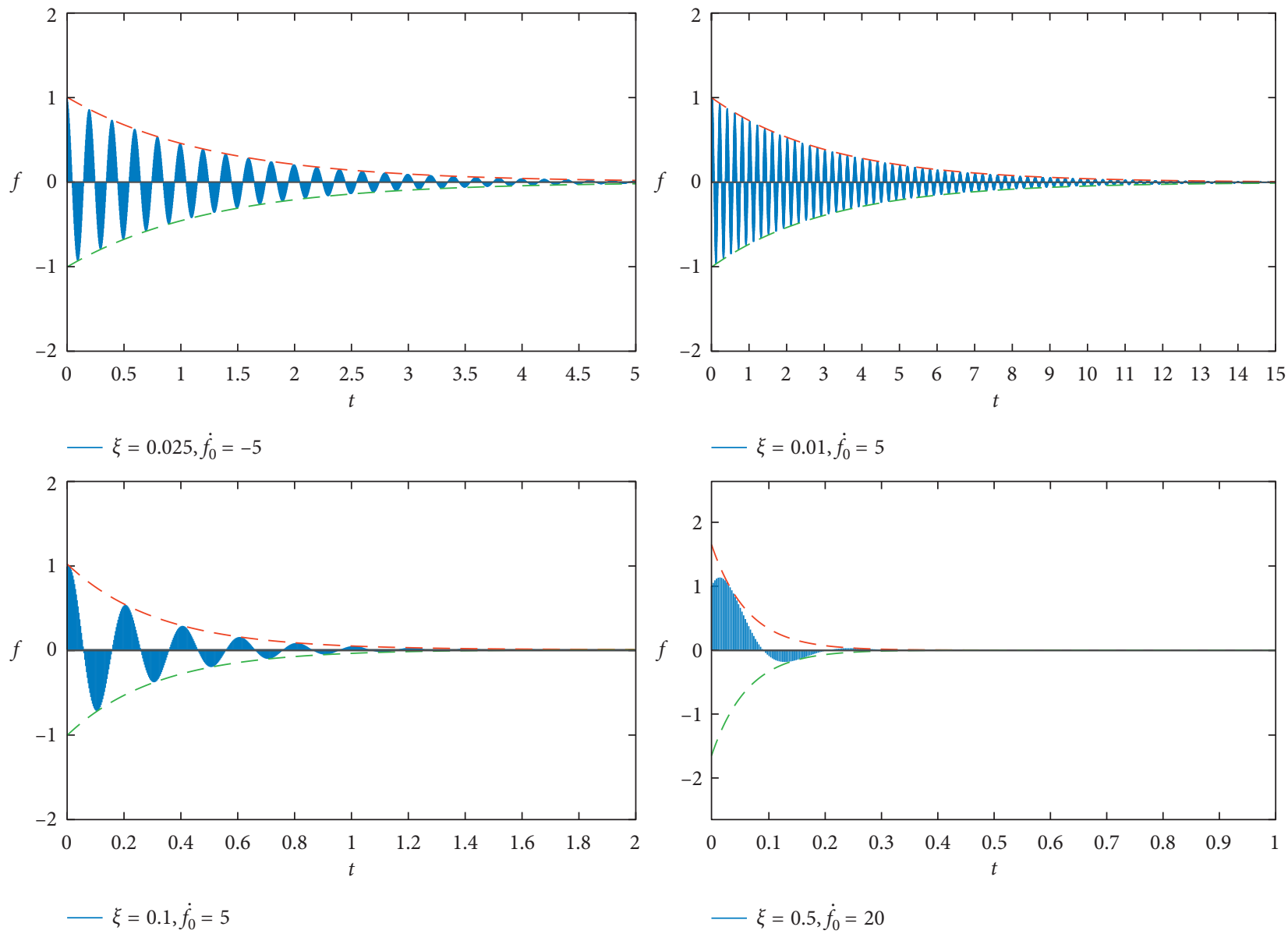

(b)

FIGURE 5: (a) Evolution of the cooperation system with the same knowledge potential difference and different initial profit rate. (b) Evolution of the cooperation effect with both different knowledge potential difference and different initial profit or loss rate. Note. The value of knowledge potential difference is set up as $\xi=0.025$, and the suppliers' initial profit rates are set up as $f_{0}=0,5,20,100$ in , while the suppliers' initial profit or loss rate and the knowledge potential difference are both different in each simulation in (b).

same knowledge potential difference are compared in the simulation, while in Figure 5(b) different initial profit or loss rate and different low potential difference are both considered to explore how these factors influence the evolution trajectory of the expected revenue.

In Figures 5(a) and 5(b), we could find that the effect from the suppliers' initial profitable status on the total expected return of the system is weakened, and it attenuates the system's expected return and prolongs the collaborative cycle. There is a periodic fluctuation in the symmetrical interval $\left(f_{-}, f^{+}\right)$ when $\xi<1$, which means that both competition and cooperation relationship among cooperators exist in the system. In addition, the fluctuating change of expected return of the whole system presents a periodic property. Additionally, the results can be drawn as follows. First, when the suppliers' initial profit is constant, a lower knowledge potential difference can increase the fluctuation frequency of the expected return of the system and extend the stable period. When $\xi \in(0.025,0.1)$ and $\dot{f}_{0} \in(5,20)$, the required evolution period $t^{*}$ becomes shorter, and the expected return of the system breaks through the original profit magnitude. Second, when $\xi$ is a constant variable, the suppliers' initial profits have a small positive effect on the system's expected return. If the fluctuation frequency of the initial profit or the loss is symmetrical, the expected return of the system presents a similar evolving cycle. When $t \in\left(0, t^{*}\right)$ and $\dot{f}_{0} \in(5,20)$, the expected return of the system can also break through the initial profit magnitude. Third, when $\xi \in(0,1)$, the larger the low knowledge potential difference is, the deeper the suppliers are attached to the core manufacturer's heterogeneous knowledge. On the contrary, the lower the knowledge potential difference is, the more homogenous the participators are. Particularly, if the knowledge potential is more concentrated, suppliers can be more easily replaced. Additionally, unless the core manufacturer guarantees benefits to keep the cooperative relationship stable, the lower knowledge 
potential difference magnifies the short-term volatility frequency of the system's expected return.

Based on the abovementioned results, it can be inferred that the lower the low knowledge potential difference is, the higher the short-term fluctuation frequency is; the more unstable the system is, the longer the stable period lasts. If the low knowledge potential difference is constant, the higher the initial profits of the suppliers and the greater the short-term profit is. However, the competing factors will ultimately decrease the radical innovation's expected return.

(3) With the critical knowledge potential difference:

Under the condition of critical knowledge potential difference, the evolution trajectory of the total expected return with critical knowledge potential difference can be observed in Figure 6.

Figure 6 shows the impact on the effect of cooperation system from critical knowledge potential difference. In Figure 6, we can see that the value of critical knowledge potential difference shows a transition value between $\xi<1$ and $\xi>1$. When $t \in\left(0, t^{*}\right)$ and $t^{*} \in(0,0.5)$, the system's expected return comes to a maximum level at the time $t^{*}$. If $t \geq t^{*}$, expected return of the system appears to decrease significantly. In addition, the suppliers' initial loss has negative effect on the system's expected return. When $\dot{f}_{0} \in(-20,-8)$, the expected return decays rapidly and achieves a stable state during the time period of $t \in(0,0.5)$. Under this condition, we can draw the conclusion that if the suppliers suffer a critical short-term loss, the substitution risk to them would affect the system's stability, which is leading to the fluctuation of expected return for innovation and in turn resulting in a low efficiency. When the participants have balanced expected returns, the system can obtain the largest expected value. Otherwise, the suppliers could withdraw from the cooperation at any time, and the systems' expected return may rapidly decline to a stable state.

From the results and conclusions drawn in the abovementioned simulation, there is obvious significance for the firm to implement cooperation so as to promote and inspire innovation. It is not conducive to establish certain radical innovation pattern when there is a critical knowledge potential difference, which may result from lacking of effective inspiration and incentives. Compared with a general cooperative system, the knowledge convergence contributes to obtaining more profit or loss fluctuation in the same direction and rapidly shortens the cooperation cycle in the cooperation system with heterogeneous cooperators. Moreover, if suppliers have a critical initial loss and no cooperation advantages, regardless of the expected increase in returns or a loss in the short-term, the long-term capital and knowledge utility tends to attenuate up to the stable and balanced state.

4.2. Evolution of Interfirm Cooperation with Knowledge RentSeeking. Different from the abovementioned analysis, we make a different assumption that the core manufacturer

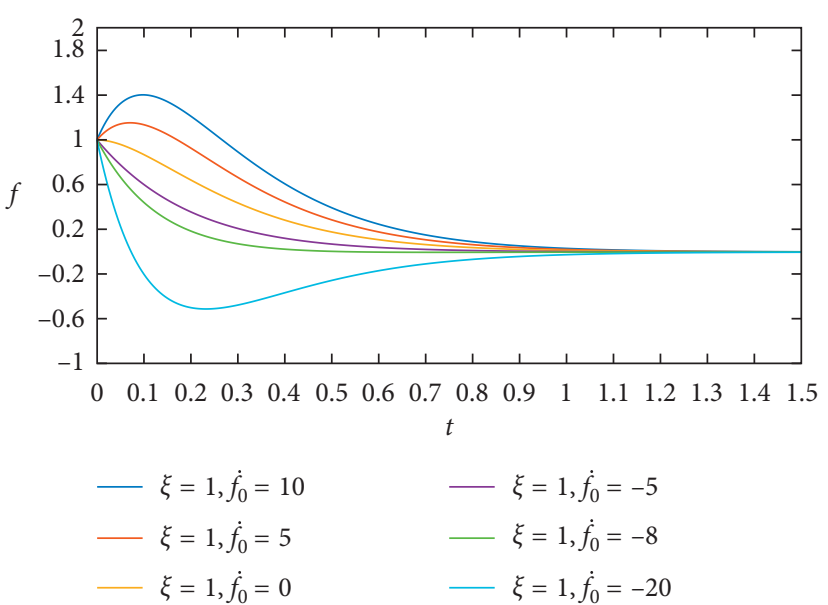

FIGURE 6: Evolution of cooperation effect with critical knowledge potential difference. Note. We consider six different experimental conditions for the suppliers: an initial profit rate with $\dot{f}_{0}=5,10$; an initial loss rate with $f_{0}=-5,-8,-20$; and no initial contributions with $\dot{f}_{0}=0$.

should implement incentive to the suppliers, and the expected initial return should be set up as the total return of the system with the initial state of a one-magnitude profit.

(1) With low knowledge potential difference:

Under the condition of low knowledge potential difference, the evolution trajectory of the total expected revenue of the cooperation system with knowledge rent-seeking behaviour can be seen in Figure 7.

In Figure 7, we can find that under the condition of low knowledge potential difference, the suppliers' rent-seeking behaviour always makes the expected return of the cooperation system unstable and divergent in the symmetric interval of $f \in\left(f_{-}\left(K_{M}, K_{S}\right), f^{+}\left(K_{M}, K_{S}\right)\right)$, and there is the possibility that the expected return could break through the initial profit magnitude. From Figure 7, some specific results can be drawn as follows. First, when there is a certain probability of rent-seeking behaviour, the smaller the benefit of the low knowledge potential difference to the systems expected profit is, the longer the duration of the stable period is. When $p\left(K_{R, S}\right)=0.5$ and $\xi \in(0.1,0.5)$, the system profit is larger than the initial level. Second, when the knowledge potential difference is a certain value, the lower probability of rent-seeking would decrease the system profits. Particularly, when $p\left(K_{R, S}\right)<0.3$, the system profit is lower than the initial level, and the suppliers can absorb and integrate the needed knowledge conveniently. However, the system is still divergent and unstable. Even if there can be a steady-state equilibrium solution generated by suppliers, it would only be a transient equilibrium, and the suppliers would again seek a new equilibrium. Based on the simulation results, it can be inferred and proved that a stable equilibrium 


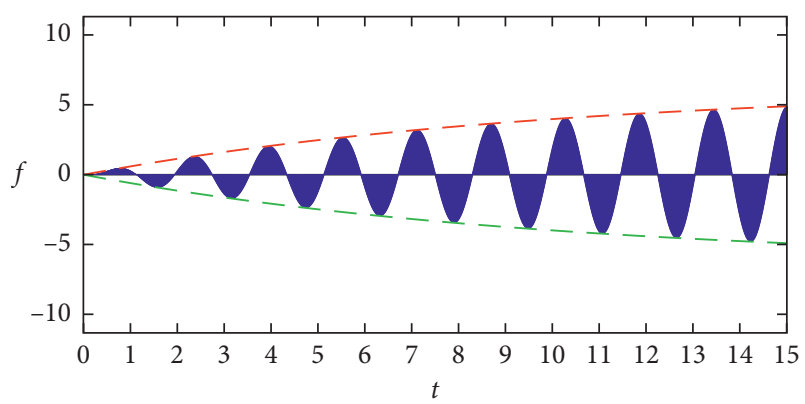

$-\xi=0.025, p=0.5$

(a)

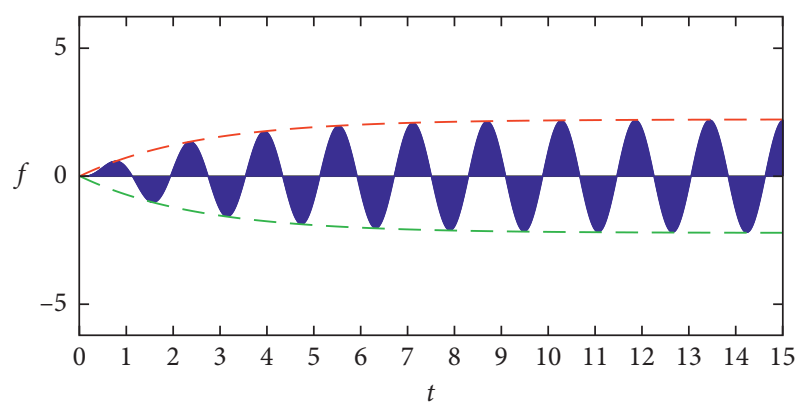

$-\xi=0.1, p=0.7$

(c)

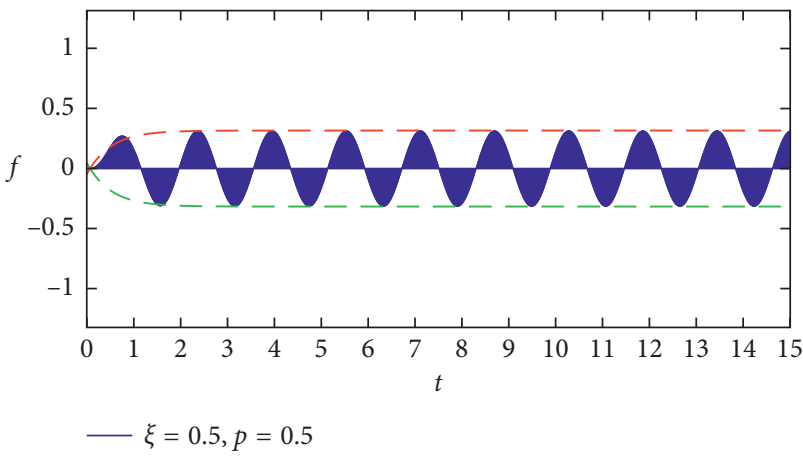

(e)

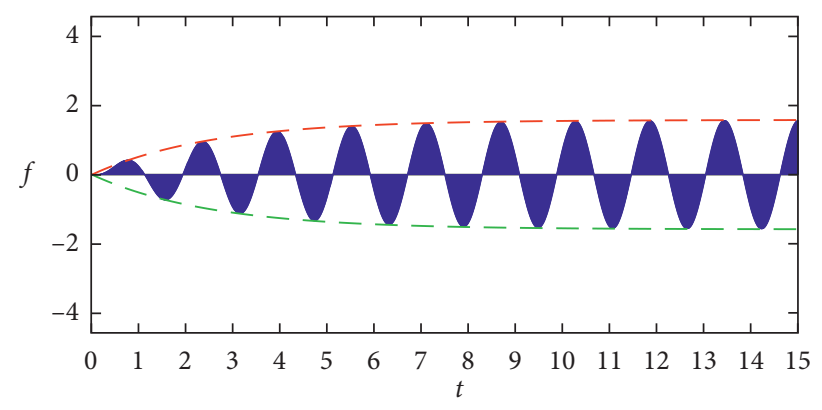

$-\xi=0.1, p=0.5$

(b)

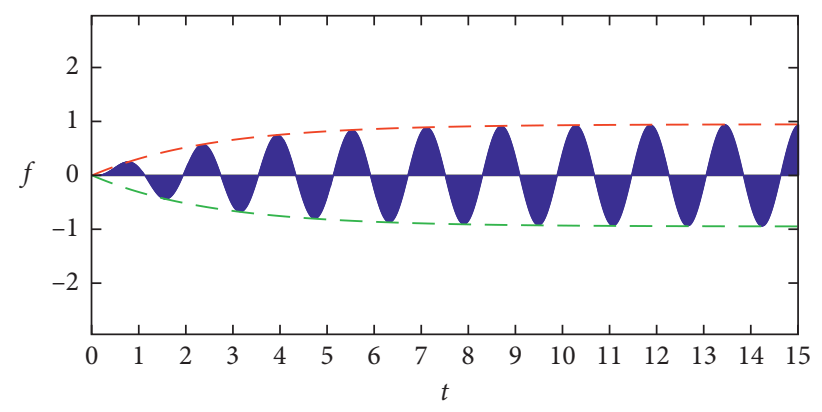

$-\xi=0.1, p=0.3$

(d)

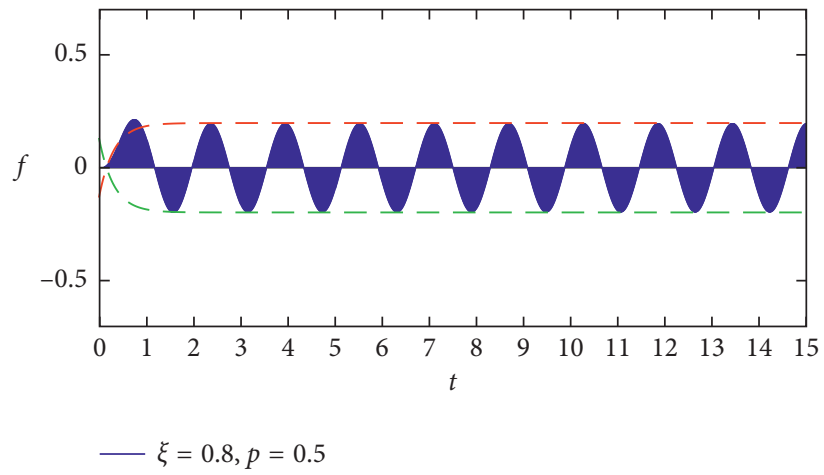

(f)

Figure 7: Impact on the system evolution from low knowledge potential difference. Note. The value of the low knowledge potential difference is set up as $\xi=0.025,0.1,0.5,0.8$, and the suppliers' rent-seeking behaviour probabilities are set up as $p=\{0.3,0.5,0.7\}$, respectively, in each simulation experiment.

state through self-adjustment can be reached only through continuous imitation, learning, and adjustments made by the suppliers.

(2) With high knowledge potential difference:

Under the condition of high knowledge potential difference with knowledge rent-seeking behaviour, the evolution trajectory of the total expected revenue can be seen in Figure 8 .

In Figure 8, we can discover that high knowledge potential difference aggravates the instability and the divergence of the expected system's return in the interval of $f \in\left(f_{-}\left(K_{M}, K_{S}\right), f^{+}\left(K_{M}, K_{S}\right)\right)$ with different probability of rent-seeking behaviour. Moreover, the expected return of the system never reaches the initial value and generates a sharp decrease. Although the increase in the suppliers' rentseeking probability may lead to a slight increase in the system's expected return in certain period, the expected return of the system shows a sharp decrease basically. Apart from that, some other conclusions can be drawn as follows. First, when the suppliers have the same probability of rent-seeking behaviour, higher knowledge potential difference could place negative effect on the system's benefit more severely, making the system's expected return decrease sharply. Second, when there is a high knowledge potential difference, the negative effect on the system's return is larger with $p\left(K_{R, S}\right) \in(0,0.5)$ than that with $p\left(K_{R, S}\right)=0.5$. Meanwhile, the negative 

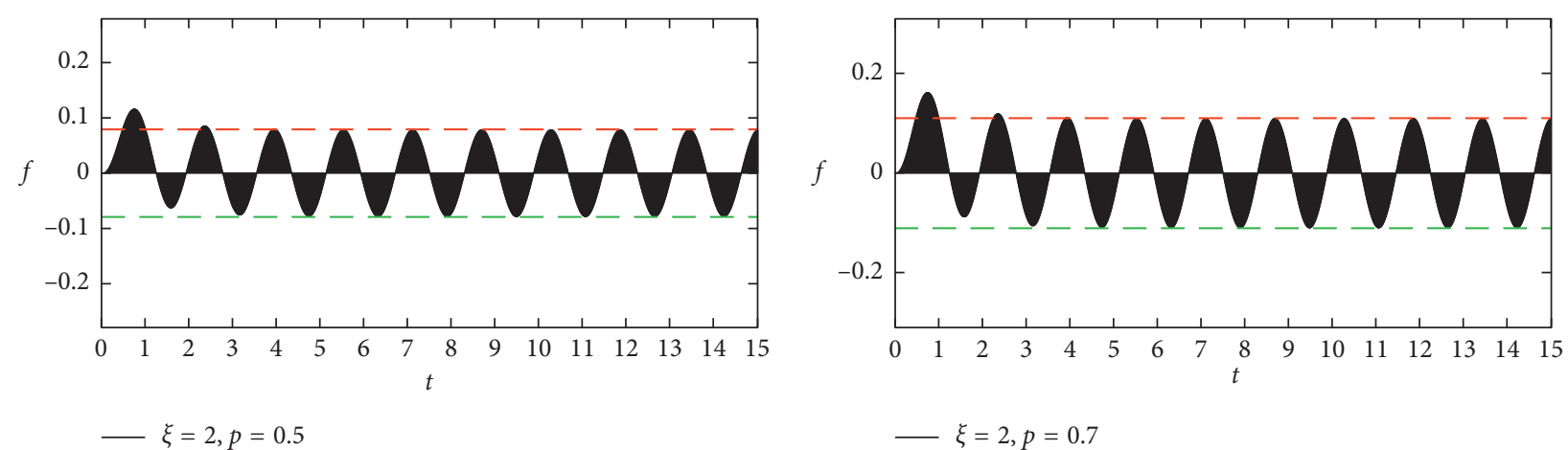

(a)

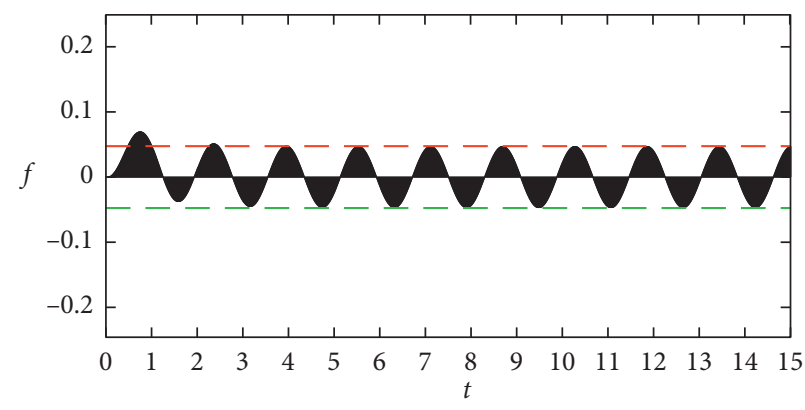

(b)

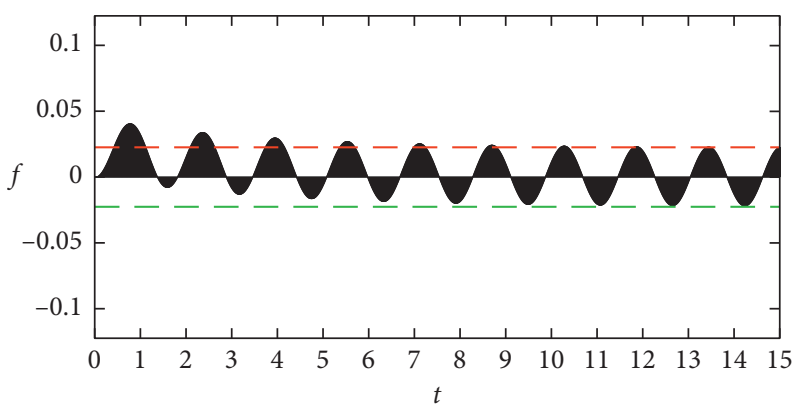

$\zeta=2, p=0.3$

$-\xi=7, p=0.5$

(c)

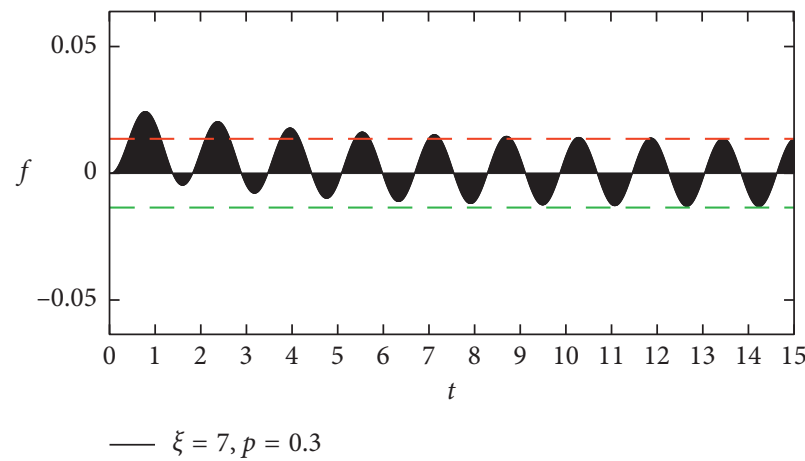

(e)

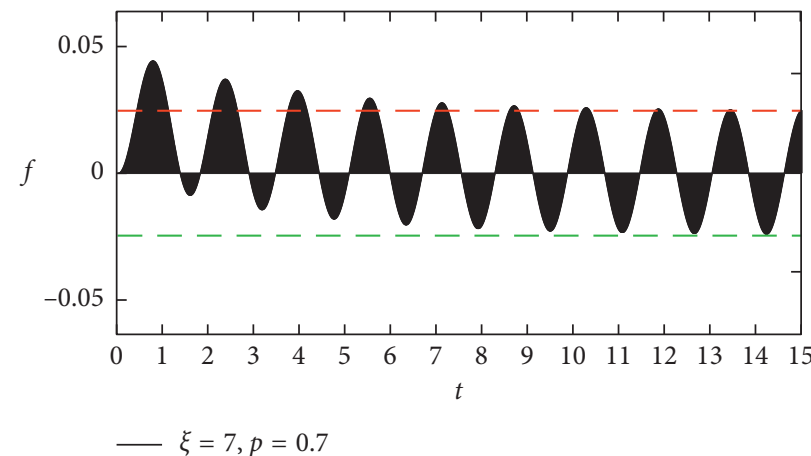

(f)

FIGURE 8: Impact on the system evolution from high knowledge potential difference. Note. Two different experimental states are considered. The value of the high knowledge potential difference is set up as $\xi=\{2,7\}$, and the suppliers' rent-seeking behaviour probability is set up as $p=\{0.3,0.5,0.7\}$.

effect on the system's return with $p\left(K_{R, S}\right) \in(0.5,1)$ is lower than that with $p\left(K_{R, S}\right)=0.5$. Thus, it can be inferred from the simulation that the system's unstable state should be obviously relevant to the incentive mechanism proposed by the core manufacturer. Meanwhile, since the expected benefits of the scarce knowledge owned by each individual may be sacrificed, the suppliers are driven to maximize their own expected return and to exhibit knowledge rent-seeking behaviour.

Overall, under the condition of specific high knowledge potential difference with knowledge rentseeking behaviour, even some incentive methods implemented to adjust the suppliers' rent-seeking behaviour matters little on achieving the system's expected return, while under the condition of low knowledge potential difference, the suppliers' selfadaption so as to manipulate the knowledge rentseeking behaviour still cannot change the divergent and unstable states of the system's expected return in the long term.

(3) Incentive impact from the core manufacturer:

For the core manufacture's being in the key position of the cooperation system, any incentive methods could be implemented by the core manufacture so as to promote the cooperation and achieve the expected outcome, especially for radical innovation. Therefore, on the above presumed parameters' setup, 
simulation on how the incentive from the core manufacture influencing the evolution of the whole expected return is conducted in the section and the evolving trajectory can be seen in Figure 9.

Figure 9 shows the relationship between the system's expected return and the incentive mechanism proposed by the core manufacture, and some conclusions can be drawn. First, when $\eta \longrightarrow 1$, lower knowledge potential difference will contribute to the incensement in expected return of the system with a multiplied effect, which may generate a high probability of radical innovation theoretically. Second, when $0<\eta<1$, the expected return of the system increases as the change rate of the incentives increases. However, when $\eta>1$, the expected return of the system decreases as the change rate of incentives increases. Particularly, almost within the range $\eta \in(1.2,2)$, there is no obvious increase in the changes of system expected return.

Thus, under the condition of critical knowledge potential difference, the core manufacture's incentive effect on the suppliers is weakened significantly. Especially, when there is a high knowledge potential difference, the increase of the system's synergistic expected return will decrease from the initial level. However, if the core manufacturer could predict the changes of the system's expected return according to the market demand as accurate as possible and could propose the prior incentive to the suppliers, it may do help to the expected return. Meanwhile, if the core manufacturer implements real-time incentives to suppliers, which means that the incentive change range reflects the market changes, the system synergistic expected return could reach the maximum within the presumed condition. However, the core manufacturer's postincentives effect could be weakened significantly, but the system's expected return can also be in a relatively good status. Overall, it can be inferred from the simulation that when the core manufacturer implements incentives towards the suppliers, the impulse effect of rentseeking behaviour can be reduced, and the hindrance caused by the knowledge potential difference can be weakened to some extent.

\section{Conclusion}

Based on the new technologies being widely implemented in various industries, interfirm cooperation can be seen as a significant and effective way for exploring radical innovation. The intrinsic mechanism of the interfirm cooperation, especially in high-tech industry, has been a hot issue recently. In this article, a framework of interfirm cooperation, with a core manufacture and its upstream counterparties, and its evolving mechanism in the reverse-chain radical innovation are established from the perspective of the fundamental role played by knowledge collaboration. From both subjective and objective viewpoints, a dynamic evolution model of interfirm cooperation for innovation is constructed on the theory of vibration mechanics, and its dynamic cooperation effect is discussed through numerical and simulation analyses mainly on the influential factors of knowledge potential difference and knowledge rent-seeking

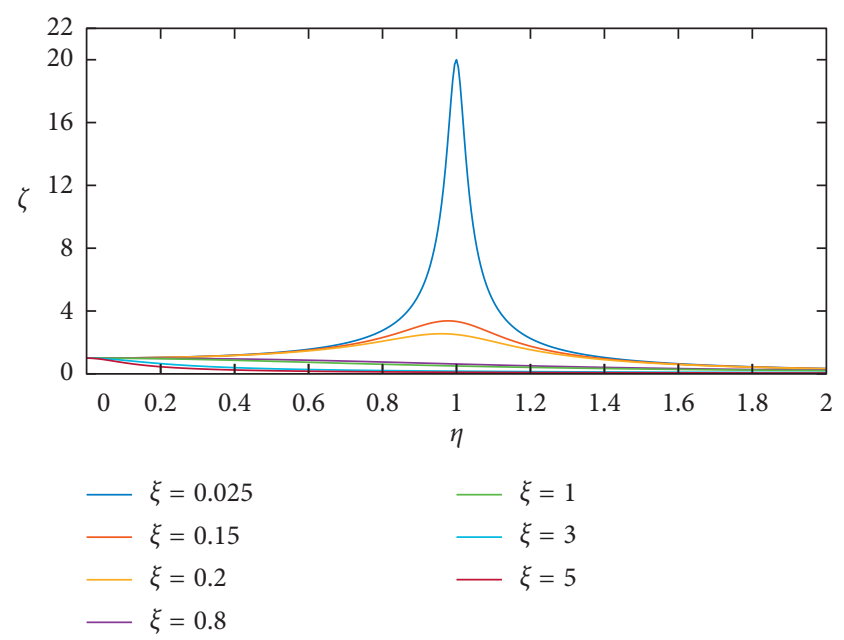

FIGURE 9: Evolution of the impact on systemic expected return from incentives frequency. Note. The value of knowledge potential difference is set up as $\xi=\{0.025,0.15,0.2,0.8,1.0,3.0,5.0\}$ in the simulation. The horizontal axis indicates the proportion of the incentives' change frequency to the system return change frequency, and its value range is set up with $\eta \in(0,2)$. The vertical axis expresses the change of the system's synergetic expected return defined as $\varsigma$, which could be presented as the amplification effect for radical innovation in the cooperation system.

behaviour. Three types of knowledge potential differences and two types of knowledge rent-seeking behaviours are considered respectively in the paper.

Some critical conclusions are drawn as follows. First, when upstream firms do not choose rent-seeking behaviours, high knowledge potential difference has a noncontinuous positive effect on cooperation for innovation, while low knowledge potential difference weakens this effect. Meanwhile, knowledge collaboration is not obviously helpful to innovation when the upstream firms' initial losses are particularly serious. From this, the core firm should pay more attention on the cooperation process, so as to make this sustainable as long as the returns are in line with the expectation. Second, when upstream firms have varying degrees of rent-seeking propensities, innovation performance depends on the excitation mechanism proposed by the core manufacturer. In this situation, rather than high knowledge potential difference, relatively low knowledge potential difference has positive effect on innovation when the core manufacturer adopts real-time excitation mechanisms. Therefore, from practical viewpoint, the organized form between the interfirm cooperation with evaluating the participants' performance and substituting the proper partner contingently can be consider by the core firm, which may trigger some insight into the innovation in organization management. Third, contrary to our expectation, knowledge convergence among the firms does not place absolutely positive effect for innovation, but actually could lead to high risk of supplier' shortening the cooperation cycle.

Therefore, through the possession of the key strategic knowledge resources, the core firm in the interfirm cooperation system should focus on improving the suppliers' 
dependence and exciting their motivation in the knowledge collaboration. When the core firm imposes excitation or constraints on the periphery firms under knowledge convergence, periphery firms should continue to expand their self-knowledge through acquiring external knowledge and maximize the whole return of the cooperation system as much as possible. If there is extreme higher knowledge potential difference, core firms should try to reduce the difficulty of knowledge absorbing activities, and the periphery firms should not only maximize the use of existing knowledge but also improve the ability of integrating knowledge collaboratively, so that it could be helpful for innovation emerging in this new pattern of interfirm cooperation.

\section{Data Availability}

The authors provided the pseudocode of the experimental simulation in this article so that this can make it easier for the reviewers or the potential users to analyse, which could also be beneficial for future improvement of this article. All the codes of this article will be supplied as supplementary information.

\section{Conflicts of Interest}

The authors declare that they have no conflicts of interest.

\section{Acknowledgments}

This research was supported by the National Planning Office of Philosophy and Social Science (Grant no. 19BJY255), the National Natural Science Foundation of China (Grant nos. 71372181, 71301078, and 71502085), MOE (Ministry of Education in China) Youth Foundation Project of $\mathrm{Hu}-$ manities and Social Sciences (Grant no. 17YJC790002), Key Projects of Social Science by Jiangsu Province (Grant no. 18EYA002), the Sponsorship of Jiangsu Overseas Visiting Scholar Program for University Prominent Young and Middle-Aged Teachers and Presidents in the year of 2018, and the Teaching Reform Project of Nanjing Normal University in the year of 2019 (Grant no. 2019NSDJG025).

\section{Supplementary Materials}

(1) Pseudocode for the self-organized effect of the intercooperation system in knowledge interaction stage with different parameters of "Potential" and "Beta", while parameters "Potential" and "Beta" should be both endowed with $0.8,1.0$, and 1.3 , respectively, to check the status. (Supplementary Materials)

\section{References}

[1] R. D. Dewar and J. E. Dutton, "The adoption of radical and incremental innovations: an empirical analysis," Management Science, vol. 32, no. 11, pp. 1422-1433, 1986.

[2] H. Gatignon, M. L. Tushman, W. Smith, and P. Anderson, “A structural approach to assessing innovation: construct development of innovation locus, type, and characteristics," Management Science, vol. 48, no. 9, pp. 1103-1122, 2002.

[3] C. M. Christensen, M. Raynor, and R. Mcodonald, "What is disruptive innovation?" Harvard Business Review, vol. 93, no. 12, pp. 44-53, 1997.

[4] D. Slepniov, B. V. Wæhrens, and J. Johansen, "Dynamic roles and locations of manufacturing," Journal of Manufacturing Technology Management, vol. 25, no. 2, pp. 198-217, 2014.

[5] A. L. Tucker and S. J. Singer, "The effectiveness of management-by-walking-around: a randomized field study," Production and Operations Management, vol. 24, no. 2, pp. 253-271, 2015.

[6] D. R. Soriano, D. P. Marqués, C. D. Carañana, and M. P. Ortíz, "How to create international business competences and their impact on firm performance," European Journal of International Management, vol. 8, no. 3, pp. 279-292, 2014.

[7] G. Hamel and C. K. Prahalad, Competing for the Future, Harvard Business School Press, Boston, MA, USA, 1994.

[8] W. Shan, G. Walker, and B. Kogut, "Interfirm cooperation and startup innovation in the biotechnology industry," Strategic Management Journal, vol. 15, no. 5, pp. 387-394, 1994.

[9] D. J. Teece, "Profiting from technological innovation: implications for integration, collaboration, licensing and public policy," Research Policy, vol. 15, no. 6, pp. 285-305, 1986.

[10] B. S. Tether, "Who co-operates for innovation, and why," Research Policy, vol. 31, no. 6, pp. 947-967, 2002.

[11] A. K. Gupta and V. Govindarajan, "Knowledge flows within multinational corporations," Strategic Management Journal, vol. 21, no. 4, pp. 473-496, 2015.

[12] M. Segarra-Ciprés, V. Roca-Puig, and J. Carlos Bou-Llusar, "External knowledge acquisition and innovation output: an analysis of the moderating effect of internal knowledge transfer," Knowledge Management Research \& Practice, vol. 12, no. 2, pp. 203-217, 2014.

[13] W. Becker and J. Dietz, "R\&D cooperation and innovation activities of firms-evidence for the German manufacturing industry," Research Policy, vol. 33, no. 2, pp. 209-223, 2004.

[14] B. Dachs, B. Ebersberger, and A. Pyka, "Why do firms cooperate for innovation? A comparison of Austrian and Finnish CIS3 results," International Journal of Foresight and Innovation Policy, vol. 4, no. 3-4, pp. 200-229, 2008.

[15] R. B. Bouncken, V. Fredrich, P. Ritala, and S. Kraus, "Coopetition in new product development alliances: advantages and tensions for incremental and radical innovation," British Journal of Management, vol. 29, no. 3, pp. 391-410, 2018.

[16] P. de Faria, F. Lima, and R. Santos, "Cooperation in innovation activities: the importance of partners," Research Policy, vol. 39, no. 8, pp. 1082-1092, 2010.

[17] D. Giovanni, "The nature of the innovative process," in Technical Change and Economic Theory, G. Dosi, C. Freeman, R. Nelson, G. Silverberg, and L. Soete, Eds., pp. 221-238, Pinter, London, UK, 1988.

[18] R. Cowan, "Network models of innovation and knowledge diffusion," in Clusters, Networks and Innovation, S. Breschi and F. Malerba, Eds., Oxford University Press, Oxford, UK, 2005.

[19] K. Wersching, "Schumpeterian competition, technological regimes and learning through knowledge spillover," Journal of Economic Behavior \& Organization, vol. 75, no. 3, pp. 482493, 2010.

[20] R. Belderbos, M. Carree, B. Lokshin, and B. Lokshin, "Complementarity in R\&D cooperation strategies," Review of Industrial Organization, vol. 28, no. 4, pp. 401-426, 2006. 
[21] M. Cincera, L. Kempen, B. Van Pottelsberghe, R. Veugelers, and C. Villegas, "Productivity growth, R\&D and the role of international collaborative agreements: some evidence for Belgian manufacturing companies," Brussels Economic Review, vol. 46, no. 3, pp. 107-140, 2003.

[22] P. Patrick, L. Dirk, and T. P. Frank, "Attracting solutions in crowdsourcing contests: the role of knowledge distance, identity disclosure, and seeker status," Research Policy, vol. 48, no. 1, pp. 98-114, 2019.

[23] L. Pittaway, M. Robertson, K. Munir, D. Denyer, and A. Neely, "Networking and innovation: a systematic review of the evidence," International Journal of Management Reviews, vol. 56, no. 3-4, pp. 137-168, 2004.

[24] M. Bengtsson and M. Johansson, "Managing coopetition to create opportunities for small firms," International Small Business Journal: Researching Entrepreneurship, vol. 32, no. 4, pp. 401-427, 2014.

[25] R. B. Bouncken, J. Gast, S. Kraus, and M. Bogers, "Coopetition: a systematic review, synthesis, and future research directions," Review of Managerial Science, vol. 9, no. 3, pp. 577-601, 2015.

[26] K. Laursen and A. Salter, "Open for innovation: the role of openness in explaining innovation performance among U.K. manufacturing firms," Strategic Management Journal, vol. 27, no. 2, pp. 131-150, 2006.

[27] L. Collins, "Opening up the innovation process," Engineering Management, vol. 16, no. 1, pp. 14-17, 2006.

[28] B. Elango and S. Chen, "Learning to manage risks in international R\&D joint ventures through ownership decisions," Management Decision, vol. 50, no. 8, pp. 1425-1444, 2012.

[29] W. Bönte and M. Keilbach, "Concubinage or marriage? Informal and formal cooperations for innovation," International Journal of Industrial Organization, vol. 23, no. 3-4, pp. 279-302, 2005.

[30] C. Rueda-Armengot and M. Peris-Ortiz, "The emigrant entrepreneur: a theoretical framework and empirical approximation," International Entrepreneurship and Management Journal, vol. 8, no. 1, pp. 99-118, 2012.

[31] B. Cassiman and R. Veugelers, "In search of complementarity in innovation strategy: internal R\&D and external knowledge acquisition," Management Science, vol. 52, no. 1, pp. 68-82, 2006.

[32] W. M. Palmer, R. R. Nelson, and J. P. Walsh, "Links and impacts: the influence of public research on industrial R\&D," Management Science, vol. 48, no. 1, pp. 1-23, 2002.

[33] H. Ibarra, "Network centrality, power, and innovation involvement: determinants of technical and administrative roles," Academy of Management Journal, vol. 36, no. 3, pp. 471-501, 1993.

[34] T.-J. A. Peng, S. Pike, J. Chung-Hsin Yang, and G. Roos, "Is cooperation with competitors a good idea? An example in practice," British Journal of Management, vol. 23, no. 4, pp. 532-560, 2012.

[35] P. R. Tomlinson and F. M. Fai, "The nature of SME co-operation and innovation: a multi-scalar and multi-dimensional analysis," International Journal of Production Economics, vol. 141, no. 1, pp. 316-326, 2013.

[36] C. Devece, D. E. Ribeiro-Soriano, and D. Palacios-Marqués, "Coopetition as the new trend in inter-firm alliances: literature review and research patterns," Review of Managerial Science, vol. 13, no. 2, pp. 207-226, 2019.

[37] J. Gallego, L. Rubalcaba, and C. Suárez, "Knowledge for innovation in Europe: the role of external knowledge on firms' cooperation strategies," Journal of Business Research, vol. 66, no. 10, pp. 2034-2041, 2013.

[38] R. R. Nelson and S. G. Winter, "The schumpeterian tradeoff revisited," American Economic Review, vol. 72, no. 1, pp. 114-132, 1982.

[39] R. Nelson, G. Dosi, C. Helfat et al., Modern Evolutionary Economics-An Overview, Cambridge University Press, Cambridge, UK, 2018.

[40] J. C. Spender and R. M. Grant, "Knowledge and the firm: overview," Strategic Management Journal, vol. 17, no. 2, pp. 5-10, 1996.

[41] M. Müller, M. Kudic, and B. Vermeulen, "The influence of the structure of technological knowledge on inter-firm $R \& D$ collaboration and knowledge discovery: an agent-based simulation approach," Journal of Business Research, 2020, In Press.

[42] J. A. C. Baum, R. Cowan, and N. Jonard, "Network-independent partner selection and the evolution of innovation networks," Management Science, vol. 56, no. 11, pp. 20942110, 2010.

[43] R. Cowan, N. Jonard, and J.-B. Zimmermann, "Bilateral collaboration and the emergence of innovation networks," Management Science, vol. 53, no. 7, pp. 1051-1067, 2007.

[44] S. Wuyts, M. G. Colombo, S. Dutta, and B. Nooteboom, "Empirical tests of optimal cognitive distance," Journal of Economic Behavior \& Organization, vol. 58, no. 2, pp. 277302, 2005.

[45] U. Cantner and A. Meder, "Technological proximity and the choice of cooperation partner," Journal of Economic Interaction and Coordination, vol. 2, no. 1, pp. 45-65, 2007.

[46] D. C. Mowery, J. E. Oxley, and B. S. Silverman, “Technological overlap and interfirm cooperation: implications for the resource-based view of the firm," Research Policy, vol. 27, no. 5, pp. 507-523, 1998.

[47] C. Antonelli, J. Krafft, and F. Quatraro, "Recombinant knowledge and growth: the case of ICTs," Structural Change and Economic Dynamics, vol. 21, no. 1, pp. 50-69, 2010.

[48] K. J. Arrow, "The economic implications of learning by doing," The Review of Economic Studies, vol. 29, no. 3, pp. $155-173,1962$.

[49] O. E. Williamson, "Comparative economic organization: the analysis of discrete structural alternatives," Administrative Science Quarterly, vol. 36, no. 2, pp. 269-296, 1991.

[50] A. Egbetokun and I. Savin, "Absorptive capacity and innovation: when is it better to cooperate?" Journal of Evolutionary Economics, vol. 24, no. 2, pp. 399-420, 2014.

[51] I. Savin and A. Egbetokun, "Emergence of innovation networks from R\&D cooperation with endogenous absorptive capacity," Journal of Economic Dynamics and Control, vol. 64, pp. 82-103, 2016.

[52] E. M. Tur and J. M. Azagra-Caro, "The coevolution of endogenous knowledge networks and knowledge creation," Journal of Economic Behavior \& Organization, vol. 145, pp. 424-434, 2018.

[53] H. Dawid and T. Hellmann, "The evolution of R\&D networks," Journal of Economic Behavior \& Organization, vol. 105, pp. 158-172, 2014.

[54] M. V. Tomasello, N. Perra, C. J. Tessone, M. Karsai, and F. Schweitzer, "The role of endogenous and exogenous mechanisms in the formation of R\&D networks," Scientific Reports, vol. 4, no. 1, p. 5679, 2015.

[55] Z. Cui and R. Wang, "Collaboration in networks with randomly chosen agents," Journal of Economic Behavior \& Organization, vol. 129, pp. 129-141, 2016. 
[56] C. Graebner, T. Heinrich, M. Kudic, and B. Vermeulen, "The dynamics of and on networks-an introduction," International Journal of Computational Economics and Econometrics, vol. 8, pp. 229-241, 2018.

[57] T. Khanna, R. Gulati, and N. Nohria, "The dynamics of learning alliances: competition, cooperation, and relative scope," Strategic Management Journal, vol. 19, no. 3, pp. 193-210, 1998.

[58] R. B. Bouncken and V. Fredrich, "Learning in coopetition: alliance orientation, network size, and firm types," Journal of Business Research, vol. 69, no. 5, pp. 1753-1758, 2016.

[59] R. B. Bouncken, R. Pesch, and A. Reuschl, "Copoiesis: mutual knowledge creation in alliances," Journal of Innovation \& Knowledge, vol. 1, no. 1, pp. 44-50, 2016.

[60] C. M. Christensen, R. McDonald, E. J. Altman, and J. E. Palmer, "Disruptive innovation: an intellectual history and directions for future research," Journal of Management Studies, vol. 55, no. 7, pp. 1043-1078, 2018.

[61] J. L. Ferreras-Méndez, S. Newell, A. Fernández-Mesa, and J. Alegre, "Depth and breadth of external knowledge search and performance: the mediating role of absorptive capacity," Industrial Marketing Management, vol. 47, pp. 86-97, 2015.

[62] M. L. Flor, S. Y. Cooper, and M. J. Oltra, "External knowledge search, absorptive capacity and radical innovation in hightechnology firms," European Management Journal, vol. 36, no. 2, pp. 183-194, 2018.

[63] R. Roy and M. Sarkar, "Knowledge, firm boundaries, and innovation: mitigating the incumbent's curse during radical technological change," Strategic Management Journal, vol. 37, no. 5, pp. 835-854, 2016.

[64] R. Roy and S. K. Cohen, "Stock of downstream complementary assets as a catalyst for product innovation during technological change in the U.S. machine tool industry," Strategic Management Journal, vol. 38, no. 6, pp. 1253-1267, 2017.

[65] M. Romer, "Endogenous technological change," NBER Working Papers, vol. 98, no. 98, pp. 71-102, 1989.

[66] H. Haken, "Synergetics: an overview," Reports on Progress in Physics, vol. 52, no. 5, pp. 515-553, 1989. 